\title{
1 Genetic and pharmacological evidence for kinetic 2 competition between alternative poly(A) sites in yeast
}

3

Rachael E. Turner ${ }^{1}$, Paul F. Harrison ${ }^{1,2}$, Angavai Swaminathan ${ }^{1}$, Calvin A. Kraupner-Taylor ${ }^{1}$, Melissa

\section{J. Curtis ${ }^{1}$, Belinda J. Goldie ${ }^{1}$, Michael M. See ${ }^{1,2}$, Amanda L. Peterson ${ }^{4}$, Ralf B. Schittenhelm ${ }^{3}$, David}

R. Powell ${ }^{2}$, Darren J. Creek ${ }^{4}$, Bernhard Dichtl ${ }^{*}$, Traude H. Beilharz ${ }^{1^{*}}$

${ }^{1}$ Development and Stem Cells Program, Monash Biomedicine Discovery Institute and Department of Biochemistry and Molecular Biology, Monash

University, Melbourne, Victoria 3800, Australia

${ }^{2}$ Monash Bioinformatics Platform, Monash University, Melbourne, Victoria 3800, Australia

${ }^{3}$ Monash Proteomics \& Metabolomics Facility, Department of Biochemistry and Molecular Biology, Monash Biomedicine Discovery Institute,

Monash University, Melbourne, Victoria 3800, Australia

${ }^{4}$ Drug Delivery, Disposition and Dynamics, Monash Institute of Pharmaceutical Sciences, Monash University, Parkville, VIC 3052, Australia

${ }^{5}$ School of Life and Environmental Sciences, Deakin University, Geelong, Victoria 3220, Australia

Keywords: alternative polyadenylation, 3' end formation, cordycepin, mycophenolic acid, nucleotide metabolism, Saccharomyces cerevisiae

*Corresponding authors:

Traude Beilharz

Development and Stem Cells Program, Monash Biomedicine Discovery Institute and Department of Biochemistry and Molecular Biology, Monash University, Melbourne, VIC 3800, Australia Email: traude.beilharz@monash.edu Phone: +61 399029183

Bernhard Dichtl

Centre for Cellular and Molecular Biology

School of Life and Environmental Sciences

Burwood, Victoria, 3125, Australia

Email: bernhard@deakin.edu.au

Phone: +61 392517060 


\section{Abstract}

Most eukaryotic mRNAs accommodate alternative sites of poly $(A)$ addition in the $3^{\prime}$ untranslated region in order to regulate mRNA function. Here we present a systematic analysis of $3^{\prime}$ end formation factors, which revealed 3'UTR lengthening in response to a loss of the core machinery, whereas a loss of the Sen1 helicase resulted in shorter 3'UTRs. We show that the anti-cancer drug cordycepin, 3' deoxyadenosine, caused nucleotide accumulation and the usage of distal poly(A) sites. Mycophenolic acid, a drug which reduces GTP levels and impairs RNA polymerase II (RNAP II) transcription elongation, promoted the usage of proximal sites and reversed the effects of cordycepin on alternative polyadenylation. Moreover, cordycepin mediated usage of distal sites was associated with a permissive chromatin template and was suppressed in the presence of an $r p b 1$ mutation, which slows RNAP II elongation rate. We propose that alternative polyadenylation is governed by temporal coordination of RNAP II transcription and $3^{\prime}$ end processing and controlled by the availability of 3' end factors, nucleotide levels and chromatin landscape. 


\section{Introduction}

$3^{\prime}$ end processing is a critical step in eukaryotic messenger RNA (mRNA) maturation. This two-step process involves co-transcriptional endonucleolytic cleavage of the pre-mRNA transcript and the subsequent addition of a non-templated polyadenosine $(\operatorname{poly}(A))$ tail by poly $(A)$ polymerase. Cleavage site positioning is defined by a series of sequence elements within the pre-mRNA transcript that are recognised by the multisubunit complexes that form the $3^{\prime}$ end processing machinery. These cleavage and polyadenylation factors are highly conserved between eukaryotes, however, some differences in proteins and organisation exist between organisms. In the budding yeast Saccharomyces cerevisiae, three subcomplexes make up the core $3^{\prime}$ end processing machinery. These include cleavage and polyadenylation factor (CPF), cleavage factor IA (CFIA) and cleavage factor IB (CFIB) (Zhao et al., 1999, Mandel et al., 2008). Together, these interact with the nascent transcript to promote both cleavage and polyadenylation (Graber et al., 1999; fig. 1A).

The $3^{\prime}$ end processing signals involved in cleavage site recognition in yeast are generally more divergent than their mammalian counterparts and lack strong consensus sequences (Graber et al., 1999). However, in S. cerevisiae, four main sequence elements are associated with cleavage site positioning. Firstly, there is an A-rich positioning element (PE) located 10 to 30 nucleotides upstream of the cleavage site (Tian and Graber, 2012). This is the equivalent of the mammalian polyadenylation signal (PAS) and has the same optimal sequence of AAUAAA though this motif is less conserved in yeast (Zhao et al., 1999). Secondly, a UA-rich efficiency element (EE) occurs upstream of the PE sequence. The optimal sequence for the EE is UAUAUA and is generally found 25 to 40 nucleotides away from the cleavage site (Tian and Graber, 2012). This sequence is not required for cleavage but improves the efficiency of the reaction and is important in site selection (Guo and Sherman, 1996). Lastly, U-rich elements exist either downstream (DUE) or upstream (UUE) of the cleavage site. Recombinant Yth1, Ydh1/Cft2 and Yhh1/Cft1 (all CPF subunits) as well as purified CPF interact with these U-rich elements (Barabino et al., 2000, Dichtl and Keller, 2001, Dichtl et al., 2002) and mutation of these elements can result in reduced cleavage activity (Dichtl and Keller, 2001). Hrp1/Nab4, the sole CFIB subunit, interacts with the EE (Kessler et al., 1997, Chen and Hyman, 1998, Valentini et al., 1999). Rna15 (a CFIA subunit) has been found to interact with the PE motif in vitro (Gross and Moore, 2001), whereas in vivo mapping of factors on the nascent transcript suggested that binding of CFIA occurs downstream of the cleavage site (Baejen et al., 2014) similar to the CstF complex in the mammalian system (Chan et al., 2011, Mandel et al., 2008, Martin et al., 2012). Thus, the overall assembly of the $3^{\prime}$ end formation machinery on the pre-mRNA substrate appears to be conserved between yeast and human (Baejen et al., 2014).

Pre-mRNA 3' end formation is physically and functionally coupled to RNAP II transcription. Assembly of 3' end factors on an emerging poly $(A)$ site is accompanied by interactions with the carboxy terminal domain 
(CTD) of Rpb1, the largest subunit of RNAP II (McCracken et al., 1997). The CFIA subunit Pcf11 plays a central role in transmitting poly(A) site recognition to elongating RNAP II, triggering termination of transcription (Zhang et al., 2005, Sadowski et al., 2003, Barilla et al., 2001).

Many genes possess more than one potential site at which cleavage and polyadenylation may occur. This occurrence, termed alternative polyadenylation (APA), is pervasive in all studied eukaryotes and appears in up to 70\% of human and yeast genes (Derti et al., 2012, Ozsolak et al., 2010). Use of such alternate cleavage sites has the potential to impact the stability, localisation and translational efficiency of an mRNA transcript. This has been linked to biological processes such as development and proliferation as well as diseases including cancer (Mayr and Bartel, 2009, Ji et al., 2009, Sandberg et al., 2008). However, the mechanisms that govern cleavage site choice are still under investigation.

Here, we used mutant alleles of yeast core cleavage and polyadenylation factors to probe their roles in alternative polyadenylation. Mutant phenotypes were linked to global preferred usage of distal cleavage sites and 3' UTR lengthening irrespective of subcomplex membership. Similarly, the adenosine analogue cordycepin (3' deoxyadenosine) was shown to interfere with correct $3^{\prime}$ end processing and promote APA comparable to inactivation of the cleavage and polyadenylation machinery. This was linked to increased cellular nucleotides, and an enhanced transcription elongation rate in response to the drug treatment. In addition, the occurrence of APA following cordycepin treatment correlated with the size of intergenic regions and the size of nucleosome depleted regions after the stop codon in convergent genes. We propose that APA in yeast employs a balance between cleavage site strength, $3^{\prime}$ end processing factor availability, and transcriptional rate to establish a kinetic control of poly(A) site choice. 


\section{Results}

Mutations within the core cleavage and polyadenylation machinery promote lengthening of 3' UTRs.

A compendium of $S$. cerevisiae mutants with defects in the cleavage and polyadenylation machinery has been collated from members of the yeast 3 ' end formation community (supplemental file 1 table S1). This included strains with mutated subunits across the three core $3^{\prime}$ end processing subcomplexes CFIA, CFIB and CPF, as well as the non-canonical Nrd1-Nab3-Sen1 (NNS) complex (fig. 1A). This repository combined with modern transcriptome-wide analyses has provided a unique opportunity to further understand how $3^{\prime}$ end choices are globally regulated in yeast. We, therefore, sought to explore the role of individual cleavage factor subunits in cleavage site selection.

The majority of the cleavage and polyadenylation factors are essential for life necessitating the use of primarily temperature-sensitive alleles (fig. 1B). For consistency, irrespective of the severity of the mutation, duplicates of each strain were grown in rich media at $25^{\circ} \mathrm{C}$ until an $\mathrm{OD}_{600}$ of 0.6 was reached, then switched to a restrictive temperature $\left(37^{\circ} \mathrm{C}\right)$ for 1 hour before harvesting.

A representative set of seven mutants was chosen for full transcriptome-wide APA analysis. This included three mutants from the CFIA complex, rna14-1, pcf11-2 and clp1-pm, a mutant of the single protein factor CFIB, nab4-1, and three mutants from the CPF complex, ysh1-13, fip1-1 and pap1-1. With the exception of clp1-pm, these were temperature-sensitive mutants (fig. 1B). Gene expression and cleavage site choice were analysed using the targeted poly(A) tail sequencing approach Poly(A)-Test Sequencing (PAT-seq) (Harrison et al., 2015). This is a 3' end-focused deep sequencing technique that involves biotin-labelled anchor oligonucleotide primers, limited digestion and gel size selection to enrich for the final $200 \mathrm{bp}$ of polyadenylated transcripts as input into Illumina compatible sequencing libraries.

Sequencing data was processed using the tail-tools pipeline (http://rnasystems.erc.monash.edu/software/; Harrison et al., 2015). Sequencing reads were mapped to genes within the S. cerevisiae genome and the 3' end of transcripts were analysed for differences in positioning relative to the wild-type at $37^{\circ} \mathrm{C}$. Figure $1 \mathrm{C}$ shows the 3' UTR shifts associated with inactivation of the $3^{\prime}$ end processing machinery for the representative gene SUB2. Peak height reflects the number of transcripts ending at a certain position in the aligned sequence. Mutation of the RNA14, PCF11, HRP1/NAB4, YSH1, FIP1 and PAP1 genes caused a switch to more distal cleavage site usage and longer 3' UTRs. This change occurred to the greatest extent in the rna14-1 and pcf11-2 mutants where reads mapping to the proximal site were rarely found. Little change was noticeable for the clp1-pm mutant, which contains point mutations in the P-loop motif (K136A and 
A.

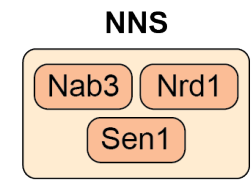
mutations have previously been shown to have limited impact on pre-mRNA $3^{\prime}$ end formation and termination in vitro (Holbein et al., 2011).
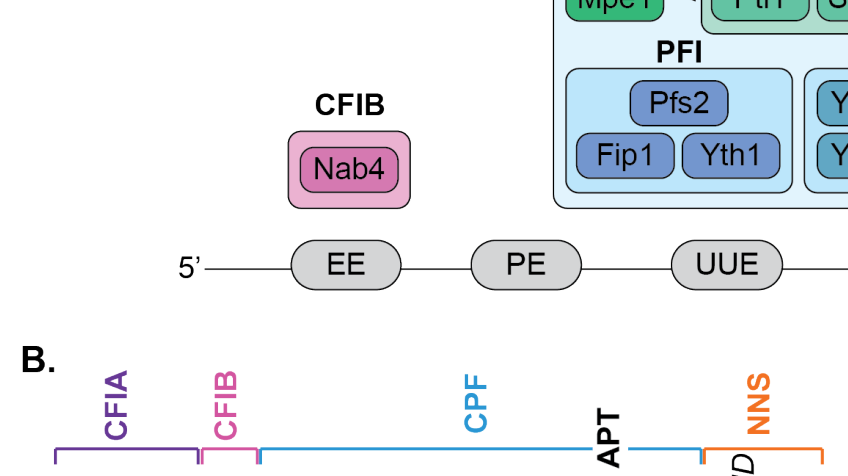

c.
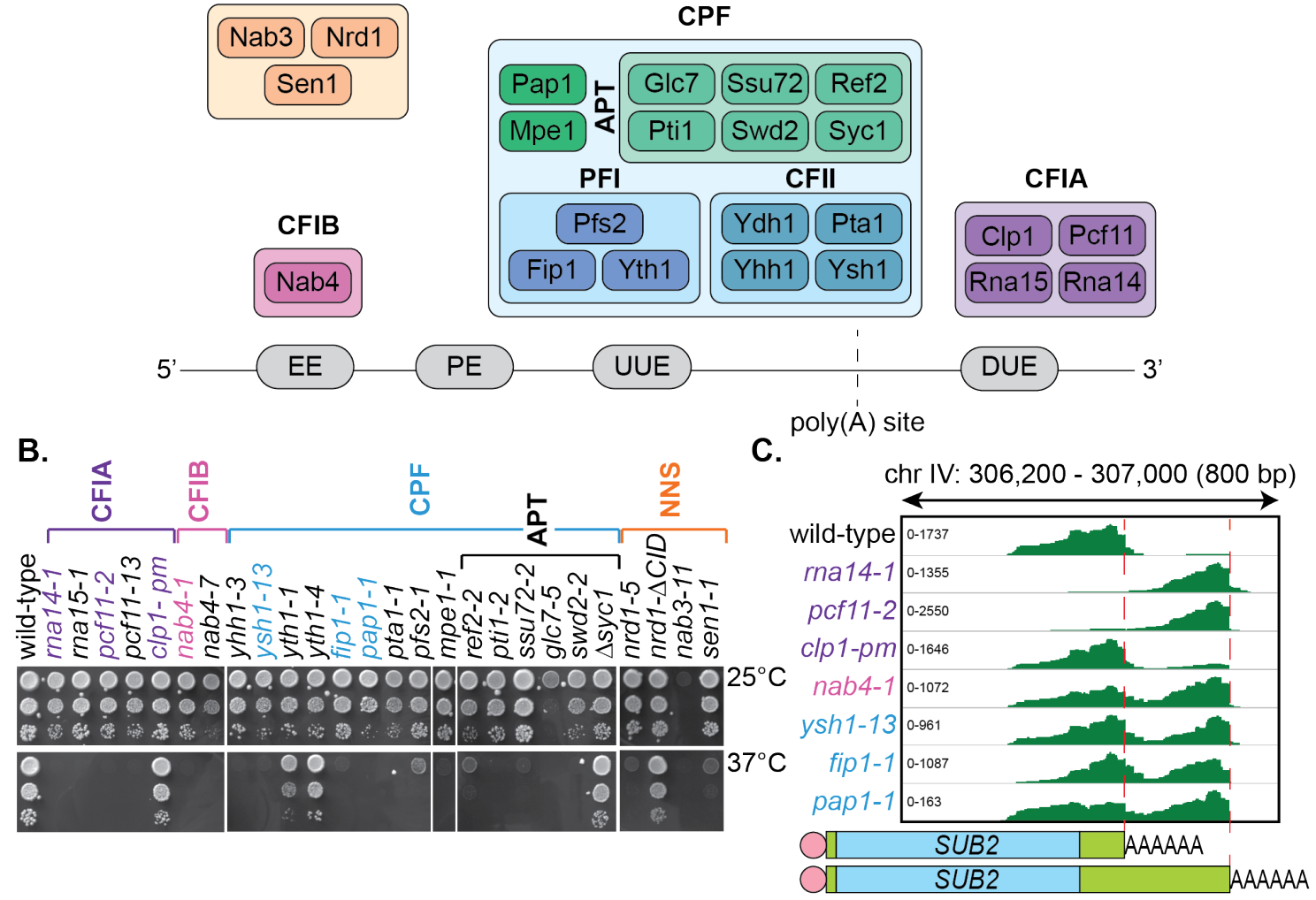

D.

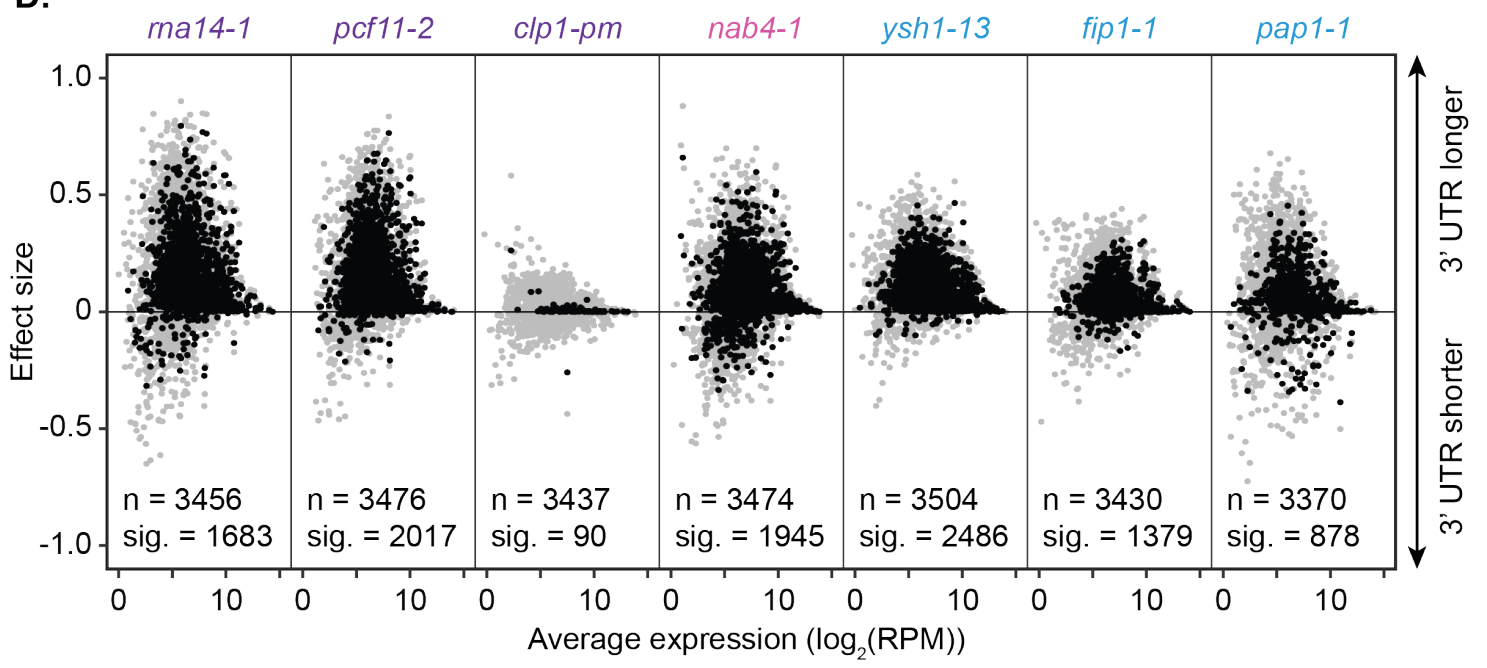

Figure 1. Mutation of the yeast cleavage and polyadenylation machinery subunits confer changes in cleavage site choice.

A. Schematic of the yeast core cleavage and polyadenylation machinery and their interactions with the nascent mRNA strand. Cleavage and polyadenylation factor (CPF), Cleavage factor IA (CFIA) and Cleavage factor IB (CFIB) are involved in canonical 3' end formation whereas the Nrd1-Nab3-Sen1 (NNS) complex represents an alternative cleavage pathway utilised by snRNAs, snoRNAs, CUTs and some mRNAs. 
B. Yeast strains, as indicated, were serially diluted 10 -fold onto YPAD rich media plates and grown at $25^{\circ} \mathrm{C}$ or $37^{\circ} \mathrm{C}$ for two days.

C. Integrative Genomics Viewer (IGV) (Robinson et al., 2011) representation of PAT-seq reads aligned to the $3^{\prime}$ end of the SUB2 gene. Indicated yeast strains were grown at $25^{\circ} \mathrm{C}$ until $\mathrm{OD}_{600} 0.6$ then switched to $37^{\circ} \mathrm{C}$ for 1 hour. Peaks indicate nucleotide depth of coverage by sequencing reads and data ranges for each sample are shown on the left. The ratio of these peaks is used to calculate $3^{\prime}$ end shifts. Schematic of $3^{\prime}$ UTR length for each peak is shown below.

D. Global 3' end shift effects of genes observed in mutants of the indicated 3' end processing factor subunits. Values are relative to the wild-type strain W303 at $37^{\circ} \mathrm{C}$ using PAT-seq data. Each dot corresponds to one gene. A positive effect size indicates a general lengthening of the $3^{\prime}$ UTR in the mutant relative to the wild-type whereas a negative effect size indicates shifts towards shorter $3^{\prime}$ UTRs. Grey dots are the estimated effect size. Where this is significant, a corresponding black dot shows the 'confect', a confident inner bound of this effect size (FDR < 0.05 ) found using the Limma and TopConfects $\mathrm{R}$ packages. The total number of detected genes (grey dots) and the number of significant

Of the 7091 genomic annotations identified by PAT-seq for our samples, 3511 were found to have two or more poly(A) sites within their 3' UTRs (supplemental file 2). Shift scores estimating the extent of 3' end shifting at $37^{\circ} \mathrm{C}$ in the seven mutants relative to the wild-type strain W303 were calculated for each of these genes. Effect size shift scores range from -1 to 1 with negative values indicating a shift to a more proximal cleavage site in the mutant and a positive shift score indicating a switch to a more distal cleavage site. An inner confidence bound, or "confect", on these effect size scores was given for genes with significantly non-zero shifts (FDR $=0.05)$ using the topconfects $R$ package (Harrison et al., 2019). Significant 3' UTR shifts were found in all seven mutants compared to the wild-type (fig. 1D). Excluding clp1-pm, 422 genes significantly changed cleavage sites in all mutants. The majority of observed shifts generated longer 3' UTRs upon mutation of the cleavage machinery indicating that functional attenuation of the individual subunits generally promoted an increase in 3' UTR length. ysh1-13 had the highest number of significant shifts with 2486 genes significantly changing their cleavage site. Of these, 2457 switched to longer 3' UTRs compared to wild-type whilst only 29 became shorter. Ysh1, an endonuclease, is assumed to be the subunit responsible for cleaving the pre-mRNA transcript (Ryan et al., 2004, Mandel et al., 2006, Garas et al., 2008) and ysh 1 mutants may cause the proximal site to be skipped due to inefficiency of the actual cleavage reaction.

Despite more genes being affected in the ysh1-13 strain, rna14-1, pcf11-2 and nab4-1 strains all showed greater extents of shifting in impacted genes with absolute average confect values of 0.150, 0.125 and 0.093 , respectively, compared to 0.086 in ysh1-13. The extent of the shift reflects the ratio of proximal to distal site usage. This suggests a key role for the CFIA and CFIB complexes in cleavage site selection. The role of these subunits in alternative polyadenylation may be attributed to a decrease in interactions with the poly(A) site sequences. It is also important to note that though the extent of switching varies in 
different mutant strains, this may be due to the severity of the mutation on protein function rather than an actual difference in the mechanisms of cleavage site recognition. Overall, inactivation of the yeast 3 ' end processing machinery appears to promote switching to more distal cleavage sites and usage of longer $3^{\prime}$ UTR with little specificity for individual subunits.

To ensure the cleavage factor mutants examined were indeed representative of the general effect 3 ' end processing machinery impairment has on APA, a subset of shifts was analysed in the full panel of mutants. This was done using the multiplexed poly(A) test (mPAT) method (Beilharz et al., 2017), which is a targeted RNA sequencing adaptation of the extension poly(A) test (ePAT) assay (Janicke et al., 2012) compatible with the Illumina MiSeq platform. The technique utilises a nested PCR to sequentially incorporate P5 and P7 extensions onto gene-specific PCR amplicons for sequencing on the Illumina flow-cell.

41 genes were chosen for APA analysis, 39 of which were shown to significantly undergo alternative polyadenylation in the previous PAT-seq experiment. Cleavage site choice in each mutant strain was compared to that of the wild-type W303 at $37^{\circ} \mathrm{C}$ and shift scores calculated for each gene (fig. 2A). For the CFIA, CFIB and CPF complexes, mutation of all but two subunits caused changes to cleavage site choice in at least a subset of the chosen genes. This was generally a switch to a more distal cleavage site and longer 3' UTR usage. However, very little shifting was seen for the $c l p 1-p m$ and $\Delta s y c 1$ mutants. Syc1 is the only nonessential subunit of the core cleavage and polyadenylation complexes (Fig. 1B; Zhelkovsky et al. 2006) indicating that its role in cleavage site choice may be negligible. 


\section{A.}

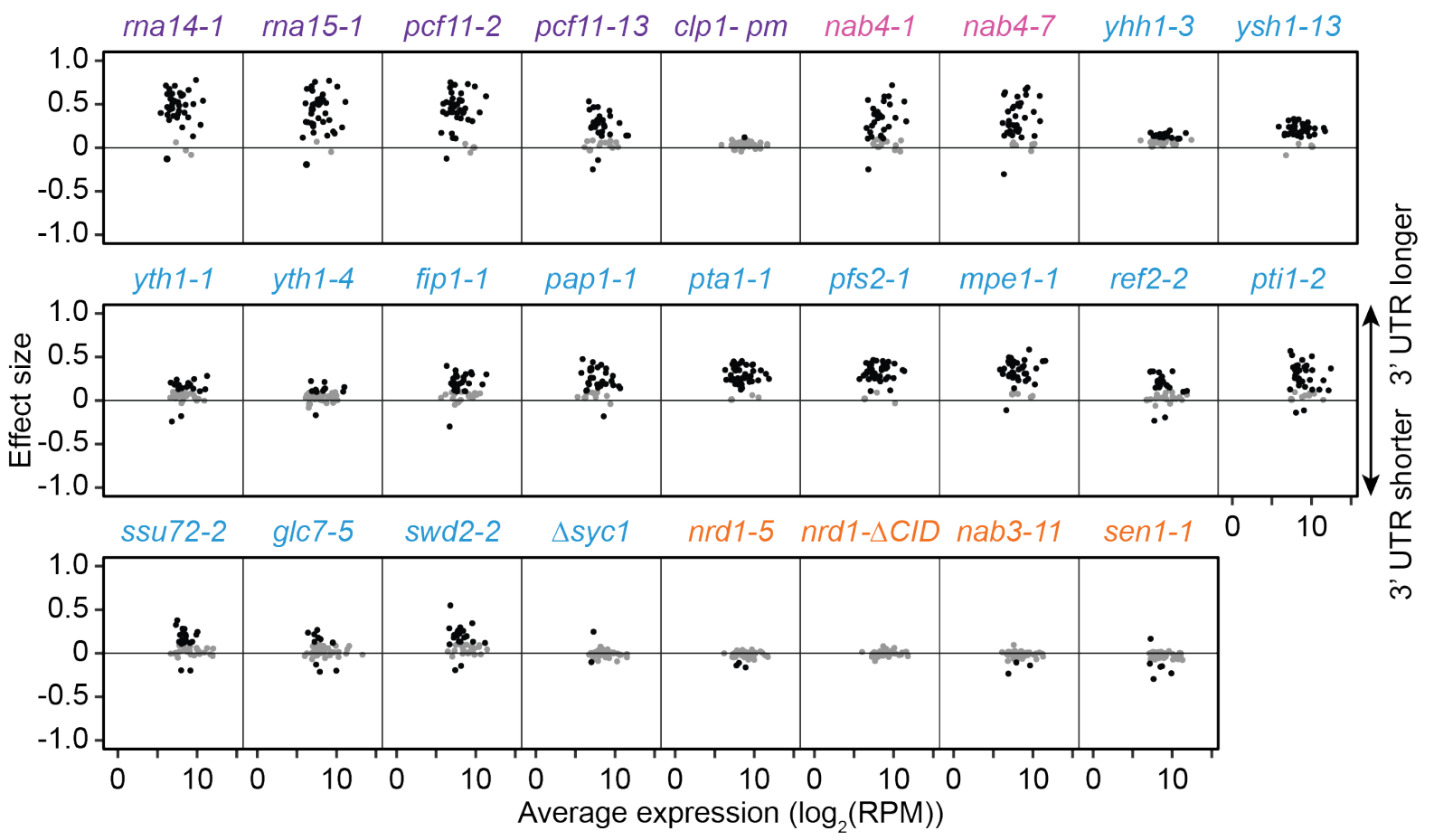

B.
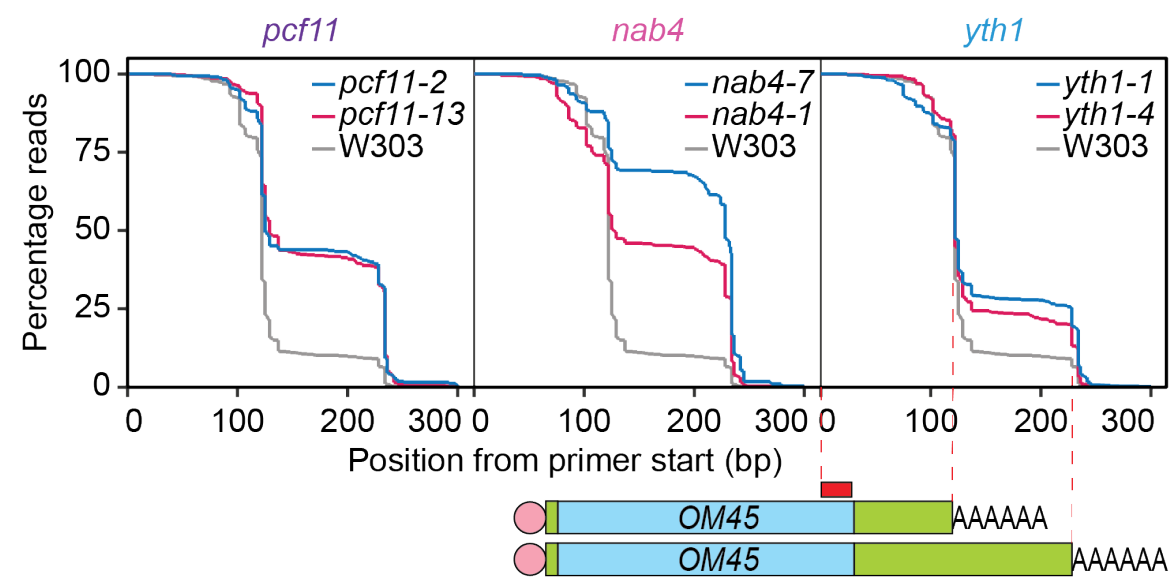

Figure 2. Mutations within the yeast cleavage and polyadenylation machinery subunits promote lengthening of mRNA $3^{\prime}$ UTRs.

A. $3^{\prime}$ end shift effects of genes observed upon mutation of the $3^{\prime}$ end processing factor subunits. Values are relative to the wild-type strain $W 303$ at $37^{\circ} \mathrm{C}$ using mPAT data. Each dot corresponds to a one gene as above. Grey dots indicate an effect size between -0.1 and 0.1 and black dots indicate an effect size less than -0.1 or greater than 0.1 . Data is representative of two biological replicates.

B. Comparison of $3^{\prime}$ end shifting in different alleles of the same 3' end processing factor. Reverse cumulative distribution plots show raw templated nucleotide length of reads aligned to the gene OM45 from mPAT data, starting from the forward primer position (red box). Mutants for a single cleavage factor are shown within the same plot in comparison to the wild-type strain W303.

In an attempt to further dissect functional requirements in APA, we analysed additional mutant alleles of selected factors. Reverse cumulative distribution plots of the 3 ' ends of read alignments were used to visualise the percentage of reads terminating at each cleavage site of the gene OM45 (fig. 2B). nab4-1 and nab4-7 mutants display defects in in vitro polyadenylation but function in in vitro cleavage (Minvielle- 
Sebastia et al., 1998). In our in vivo analyses both alleles were defective in OM45 APA demonstrating a correlation with polyadenylation but not cleavage activity. The requirement for Hrp1/Nab4 in APA likely involves its role in poly(A) site selection (Minvielle-Sebastia et al., 1998). In vitro, the yth1-1 and yth1-4 alleles both have defects in the polyadenylation step of 3 ' end formation but only yth1-4, and not yth1-1, is defective in 3' end cleavage (Barabino et al., 2000). Additionally, in vivo APA defects did not correlate with cleavage activity, since both YTH1 alleles showed comparable defects in APA (fig. 2B). The pcf11-2 allele is defective in both cleavage and polyadenylation in vitro, while the pcf11-13 allele is not (Sadowski et al., 2003). However, the latter contains mutations within the domain that interacts with the carboxyl-terminal domain (CTD) of Rpb1, the largest subunit of RNAP II (Barilla et al., 2001, Sadowski et al., 2003) and has formerly displayed defects in transcription termination (Sadowski et al., 2003). As such our APA results indicated that the interaction between Pcf11 and the transcriptional machinery was integral to APA in vivo. Overall, the results shown in figure 2B suggested that defective in vitro cleavage activity was not indicative of defective APA in vivo. In contrast, defects in APA correlated with defective in vitro polyadenylation and defective interaction with the RNAP II CTD.

Impairment of the NNS complex appeared to have little impact on cleavage site selection in this analysis. However, as only a subset of protein-coding genes require the NNS complex for transcriptional termination (Steinmetz et al., 2006, Schulz et al., 2013, Steinmetz et al., 2001), genes in which this complex plays a role may have been excluded in the MPAT analysis. To address this possibility, global APA was analysed in one mutant strain for each of the NNS subunits using the PAT-seq method as above (fig. 3A). nrd1-5 and nab311 had little to no defect in cleavage site choice with only 16 and 1 genes, respectively, shifting significantly compared to the wild-type. Interestingly, reduced function of the helicase Sen1 caused significant switching to shorter 3' UTRs for 676 genes. Of 411 genes that significantly switched cleavage site in both sen 1-1 and pcf11-2, 81.5\% were in opposing directions (fig. 3B; fig. 3C). Therefore, it appears that Sen 1 activity was required to antagonise cleavage site choice by the core $3^{\prime}$ end processing factors at a subset of genes. This was consistent with the previous report that a sen1-E1597K mutant causes premature termination and shortening of the 3' UTR of the NPL3 transcript (Steinmetz et al., 2006). We found that no significant changes in transcript levels were associated with the APA events in sen1-1 strains (data not shown), however a significant increase in gene coding region length was observed for sen1-1 responsive genes (1270.5 bp in sen1-1 APA genes and 986 bp in no APA genes, $p$-value $\left.=9.174 \times 10^{-9}\right)$. Overall, our observations are consistent with a wider role for this RNA helicase in antitermination of protein coding genes, contrasting its previously described roles in non-coding RNA termination (see discussion). 
A.

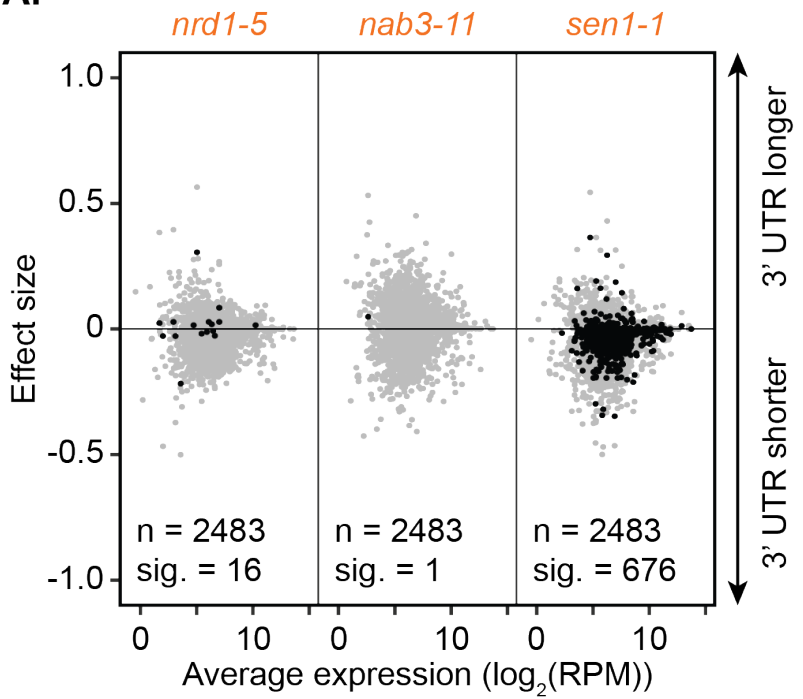

B.

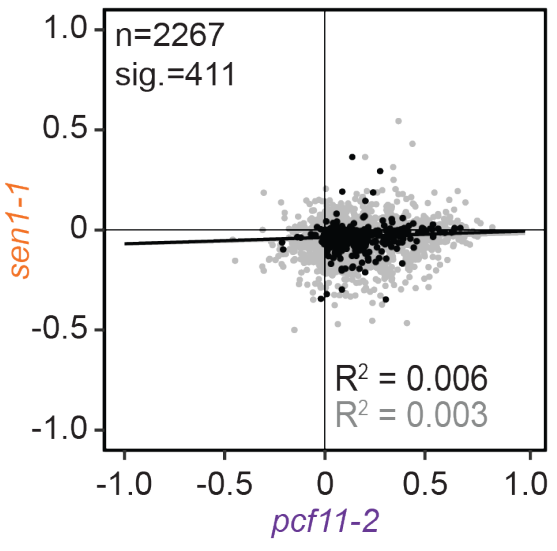

C.
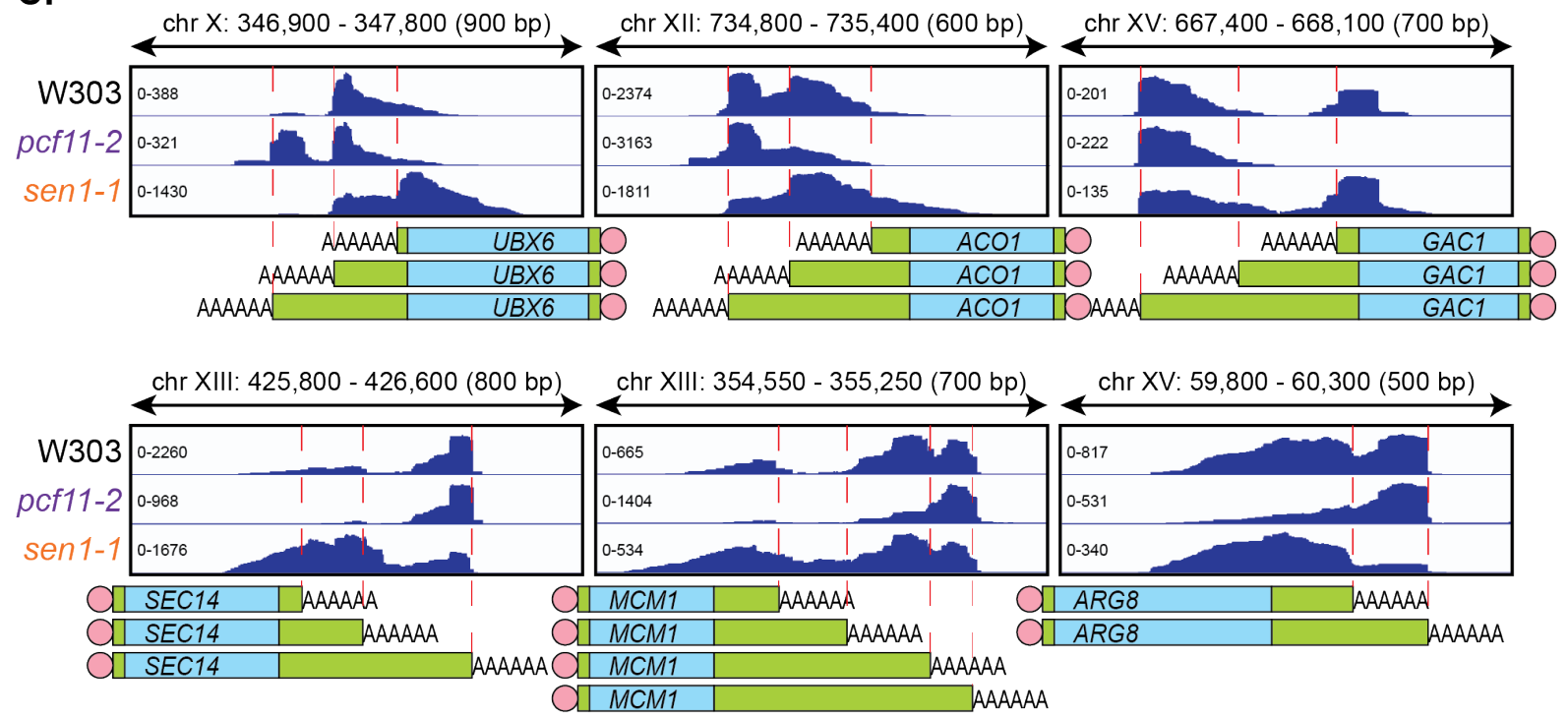

Figure 3. Sen 1 mutation promotes 3' UTR shortening.

A. $3^{\prime}$ end shift effects of genes observed upon mutation of the NNS subunits. Values are relative to the wild-type strain W303 at $37^{\circ} \mathrm{C}$ using PAT-seq data as in figure $1 \mathrm{D}$. Data is representative of two biological replicates.

B. Comparison of $3^{\prime}$ end shift effects of genes upon mutation of PCF11 (x-axis) and SEN1 (y-axis). pcf11-2 and sen $1-1$ shifts relative to their respective wild-type control at $37^{\circ} \mathrm{C}$ were compared. Grey dots indicate the estimated shift effects for all analysed features in common $(n=2267)$, black dots indicate the significant shifts $(n=411, F D R<0.05)$. Lines show the linear regression for grey and black dots respectively.

C. IGV representation of PAT-seq results aligned to the 3' end of the indicated genes in W303, pcf11-2 and sen $1-1$ yeast strains at $37^{\circ} \mathrm{C}$. Peaks indicate nucleotide depth of coverage by sequencing reads and data ranges for each sample are shown on the left. Schematic of 3' UTR length for each peak is shown below. 
Cordycepin induces lengthening of 3' UTRs.

Cordycepin, or $3^{\prime}$ deoxyadenosine, is an adenosine analogue that causes chain termination when incorporated into RNA during synthesis. We have previously demonstrated that independently of this role, cordycepin can interfere with normal 3' end formation for several genes in yeast (Holbein et al., 2009). We therefore further examined the effect of cordycepin on cleavage site choice genome-wide.

Wild-type BY4741 yeast cells were treated with a non-lethal dose of cordycepin $(20 \mu \mathrm{g} / \mathrm{ml})$ for up to 40 minutes. Alternative polyadenylation was assessed using the PAT-seq method over a time course of drug treatment. Similar to depletion of the canonical cleavage and polyadenylation machinery, cordycepin treatment promoted use of a distal cleavage site for the gene SUB2 (fig. 4A). Significant switching to alternative cleavage sites was observed for 1959 genes with the majority changing to longer 3' UTRs (fig.

4B; supplemental file 2). Therefore, cordycepin treatment generally caused a switch to more distal cleavage sites. Of note, any RNA with cordycepin incorporated will lack a 3' hydroxyl group and will therefore not be detectable by the PAT-seq assay. However, such transcripts are expected to be unstable and quickly targeted for degradation if premature termination occurs within the coding region of the gene (Kamieniarz-Gdula and Proudfoot, 2019).

How cordycepin interferes with cleavage site choice remains unknown. Genes affected by cordycepin treatment were therefore compared to those affected by mutations within the cleavage and polyadenylation machinery (supplemental fig. 1). The pattern of cleavage site switching in cordycepin treated cells was most similar to that of $p c f 11-2$ and ysh1-13, with 1391 and 1610 genes, respectively, being affected both by the drug and the mutation. However, there was also a group of 153 genes that had significant APA occurring only in the cordycepin treated samples. This variation suggested that cordycepin did not alter cleavage site usage simply by interacting with or disabling the cleavage machinery. This is consistent with our observation above that mutants defective for in vitro cleavage retained proper APA in vivo (fig 2B). Importantly, the genes that did significantly switch cleavage site in both cordycepin treated cells and the $3^{\prime}$ end factor mutants, did so in the same direction with 1365 (98.1\%) and 1592 (98.9\%) of genes in quadrants 2 and 3 for cordycepin compared to $p c f 11-2$ and ysh1-13, respectively (fig. 4C; fig. 4D). Overall, we conclude that cordycepin had a similar effect on cleavage site choice as mutations in the $3^{\prime}$ end processing machinery but that it is unlikely to cause alternative polyadenylation through direct interaction with the $3^{\prime}$ end formation factors. 
A.
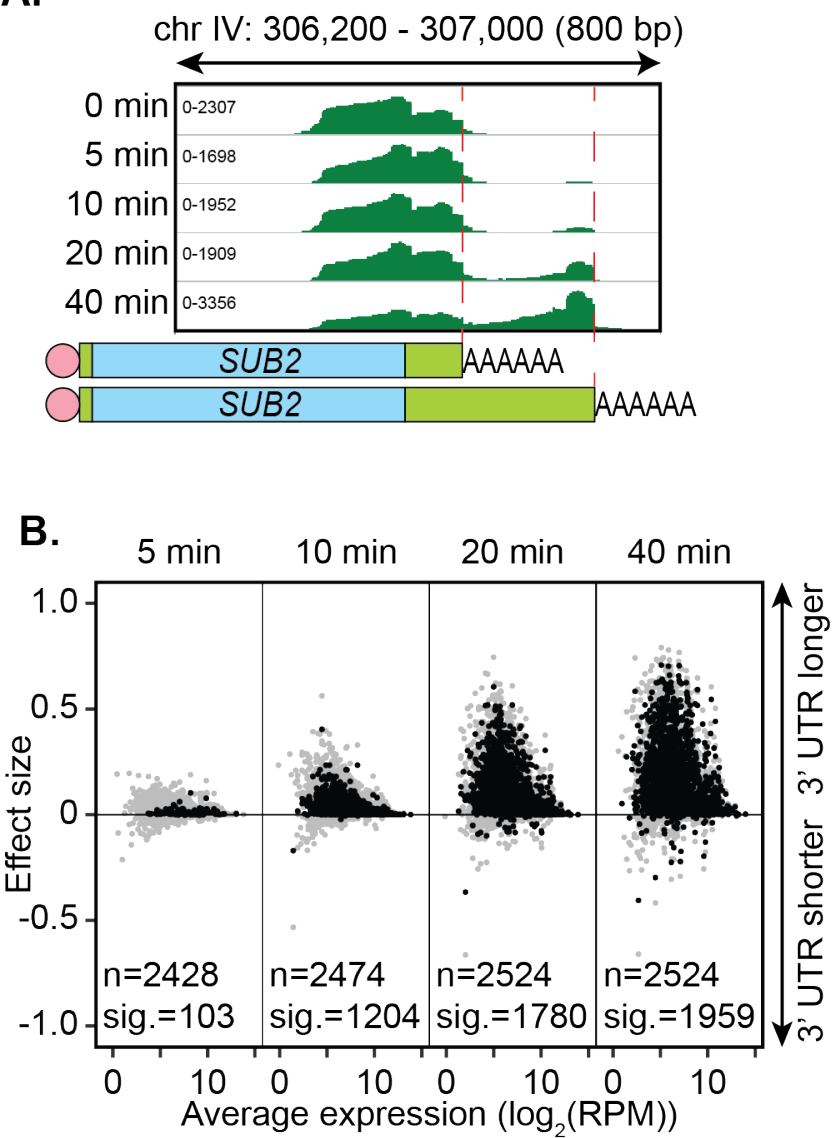

C.

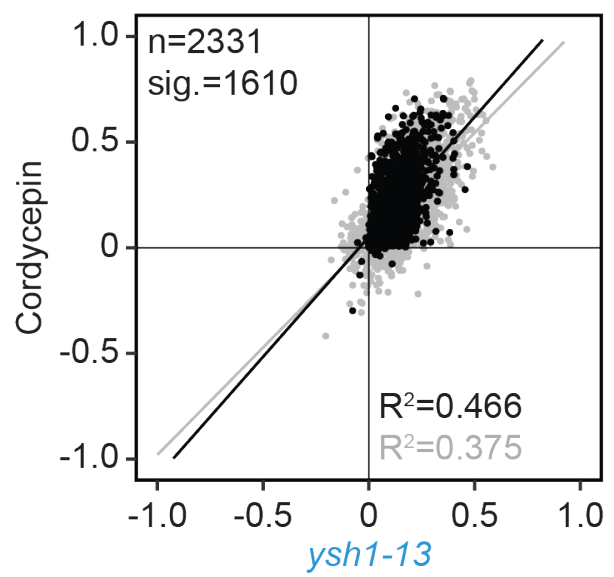

D.

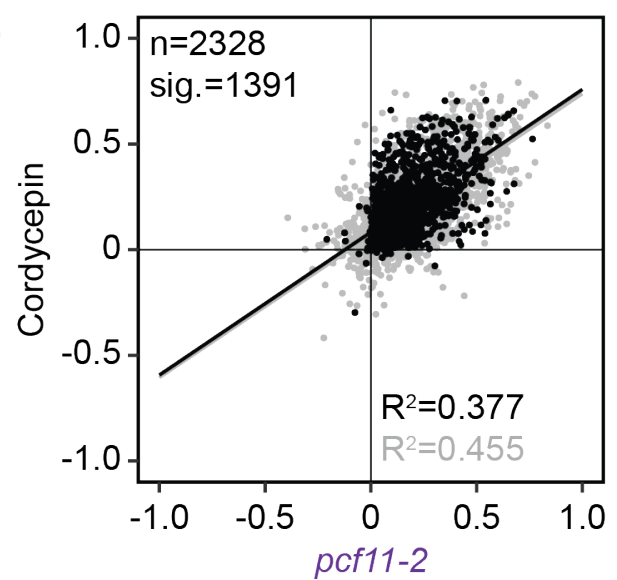

Figure 4. Cordycepin induces lengthening of 3' UTRs in yeast cells.

BY4741 cells were treated with $20 \mu \mathrm{g} / \mathrm{ml}$ cordycepin for $0,5,10,20$ or 40 minutes and changes to 3' UTR length were observed.

A. IGV representation of PAT-seq reads aligned to the 3' end of the SUB2 gene. Peaks indicate nucleotide depth of coverage by sequencing reads and data ranges for each sample are shown on the left. Schematic of 3' UTR length for each peak is shown below.

B. 3' end shift effects of genes observed upon cordycepin treatment. Values are relative to untreated cells using PAT-seq data as for figure 1D with positive values indicating lengthening following drug treatment. Data is representative of two biological replicates.

C. Comparison of $3^{\prime}$ end shift effects of genes upon mutation of YSH1 (x-axis) and after cordycepin treatment (y-axis). ysh1-13 shifts were compared to $\mathrm{W} 303$ at $37^{\circ} \mathrm{C}$ and cordycepin treatment for 40 minutes was compared to untreated BY 4741 cells at $30^{\circ} \mathrm{C}$. Grey dots indicate the estimated shift effects for all analysed features in common $(n=2331)$, black dots indicate the significant shifts $(n=1610$; FDR < 0.05). Lines show the linear regression for grey and black dots respectively.

D. Comparison of $3^{\prime}$ end shift effects of genes upon mutation of PCF11 (x-axis) and after cordycepin treatment ( $\mathrm{y}$-axis) as for $\mathrm{C}$ but with $p c f 11-2$ shifts compared to $\mathrm{W} 303$ at $37^{\circ} \mathrm{C}$. The total number of analysed features in common was 2328 and the number of significant shifts was 1391 (FDR < 0.05 ).

Cordycepin treatment, however, had an impact on the expression of the cleavage and polyadenylation

machinery (supplemental fig. 2A). The majority of the CPF complex subunits had decreased RNA expression after 40 minutes of drug treatment whereas the CFIA and CFIB encoding genes PCF11, RNA14 and 
cleavage positions, as these subunits were seen to play a key role in cleavage site selection. In addition, the NNS subunits NRD1 and SEN1 were upregulated. This might reflect a need to process the elevated level of cryptic unstable transcripts (CUTs) seen following cordycepin treatment (Holbein et al., 2009), or suggest a compensatory mechanism whereby cells under $3^{\prime}$ end stress co-opt an alternative pathway to appropriately cleave mRNA transcripts (Rondon et al., 2009).

Cordycepin treatment also provided a convenient method to assess the implications of $3^{\prime}$ UTR lengthening on translational efficiency within yeast. Polysome profiling of cells treated with cordycepin for $\mathbf{4 0}$ minutes demonstrated a decrease in polysome formation and, therefore, translation in response to cordycepin treatment (supplemental fig. 2B). This change could be due to stress from cordycepin's antifungal effect (Sugar and McCaffrey, 1998) or the global increase in 3' UTR length causing translation repression. Proteomic analysis of treated cells showed that this did not majorly transfer to global protein expression alterations with only 5 proteins significantly changing in expression (q-value 0.05 , fold change $>|1|$ ) following cordycepin treatment when assessed using data-independent acquisition (DIA) mass spectrometry (supplemental fig. 2C). However, major changes in protein expression were not expected within this short time period of cordycepin treatment, and the lack of significant results may in part reflect the inherent inability of DIA mass spectrometry to assess newly translated proteins in isolation. Of note, the cleavage factor Hrp1/Nab4 increased in abundance by $49 \%$ consistent with the upregulation of its mRNA and a cellular attempt to normalise 3'ends.

We previously showed that cordycepin-triphosphate (CoTP), rather than cordycepin, mediated the toxicity of the drug in yeast (Holbein et al. (2009). To address whether CoTP was also responsible for altered 3' end processing, $\Delta a d o 1$ and $\Delta a d k 1$ strains were subjected to cordycepin treatment (supplemental fig. 2D). Ado1, converts cordycepin to cordycepin monophosphate (CoMP), whereas Adk1 further converts CoMP to CoTP (Lecoq et al., 2001, Konrad, 1988). As $\Delta a d o 1$ cells were resistant to cordycepin-induced alternative polyadenylation for the gene OM14 and $\triangle a d k 1$ cells were not, this suggested that CoMP, not CoTP, was the mediator of APA. This further separated the roles of cordycepin in RNA incorporation and toxicity from its effect on alternative polyadenylation. In addition, $\Delta$ nrt1 cells conferred mild resistance to cordycepininduced APA, suggesting that Nrt1, a high-affinity nicotinamide riboside transporter and low-affinity thiamine transporter (Enjo et al., 1997, Belenky et al., 2008), acted as a partially redundant transporter for

Excess adenine has previously been shown to suppress cordycepin's effect on yeast cell growth (Holbein et al., 2009). To determine whether adenine addition was also able to reduce cordycepin-induced APA, wildtype BY4741 cells were treated with cordycepin and adenine. However, adenine co-treatment did not return cells to wild-type cleavage site positions (supplemental fig. 2E). Furthermore, to ask whether other 
3' deoxynucleosides can induce APA, cells were treated with the guanosine equivalent of cordycepin, 3' deoxyguanosine (supplemental fig. 2E). However, this analogue caused no changes to cleavage site choice further supporting the idea that cordycepin is unlikely to confer APA through RNA chain termination and indicates that the effect was specific to the adenosine analogue.

Cordycepin alters yeast intermediate metabolism to promote nucleotide accumulation.

The concentration of cordycepin used in our analyses did not significantly impair cell growth (supplemental

fig. 2F). To further investigate the impact of the drug treatment we analysed cellular metabolism. When grown in glucose-rich conditions, yeast preferentially ferments glucose to ethanol rather than perform aerobic respiration despite the presence of oxygen (Broach, 2012). To ask whether this was altered by cordycepin treatment, we first performed the Seahorse Energy Phenotyping assay on wild-type BY4741 yeast cells that were treated with cordycepin. This result was then compared with both DMSO treated and untreated cells. All three conditions responded to metabolic stress by increasing oxygen consumption, suggesting that cordycepin did not affect oxygen utilisation (supplemental fig. 3A). However, cordycepin treated cells did not as efficiently undergo the increase in glycolytic output observed with both control groups (supplemental fig. 3B). In yeast, an increase in extracellular acidification is expected to report carbon dioxide production rather than lactic acid synthesis and indicates a decrease in overall ethanol synthesis in cordycepin treated cells. As there was sufficient glucose in the media to support an increase in the control treated cells, this suggests that metabolites of the glycolytic pathway of cordycepin treated cells were diverted toward alternative pathways.

To probe the extent of metabolic rewiring by cordycepin, a metabolomic analysis was performed on cordycepin treated cells. Several metabolites involved in glycolytically-linked pathways were significantly upregulated following cordycepin treatment (fig. 5; supplemental file 4). The reserve carbohydrate, and stress protectant, trehalose was increased 3.8-fold, which correlated with drug-induced stress (Jain and Roy, 2009, Eleutherio et al., 2015) and signifies amplified production of storage carbohydrates. This was accompanied by a 3.1-fold increase in acetyl CoA concentration and high levels of this metabolite are associated with increased acetylation of histones (Cai et al., 2011, Donohoe et al., 2012, Lee et al., 2014) and therefore global transcriptional activity. Notably, we observed increased levels of key intermediates involved in nucleotide biosynthesis, including pentose phosphate pathway intermediates (sedoheptulose-7phosphate and putative ribulose-5-phosphate and/or xylulose-5-phosphate), inosine monophosphate (IMP), adenylosuccinate, dihydroorotate, orotate monophosphate and several nucleotides and deoxynucleotides (CDP, CTP, UDP, UTP, dCDP, dCTP, dADP and cAMP) indicating a major impact on nucleotide metabolism. Defective APA following cordycepin treatment was thus accompanied by a striking 
bioRxiv preprint doi: https://doi.org/10.1101/2020.12.01.407171; this version posted December 2, 2020. The copyright holder for this preprint (which was not certified by peer review) is the author/funder, who has granted bioRxiv a license to display the preprint in perpetuity. It is made available under aCC-BY-NC-ND 4.0 International license.

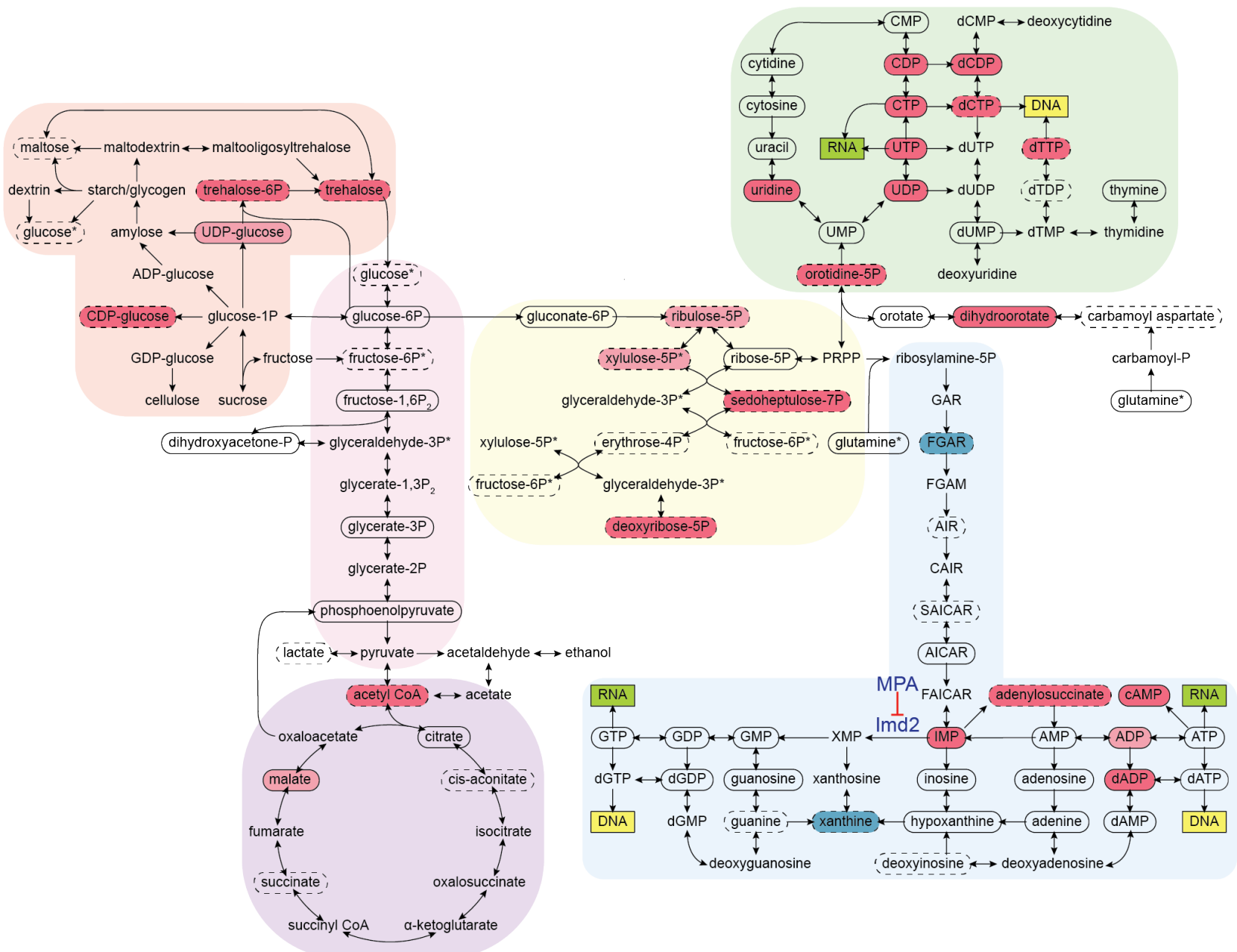

Figure 5. Cordycepin alters yeast core metabolism to promote nucleotide biosynthesis.

Yeast metabolomics pathway map showing metabolite fold changes following 40 minutes treatment with $20 \mu \mathrm{g} / \mathrm{ml}$ cordycepin. Solid circles indicate detected confirmed metabolites and dashed circles detected putative metabolites. Coloured circles show metabolites with significant fold change after cordycepin treatment with red indicating an increase in abundance and blue a decrease in abundance. Darker colour is used for metabolites with greater than $50 \%$ fold change. Pathways are based on the KEGG database and include starch and sucrose metabolism (orange), glycolysis/gluconeogenesis (pink), citrate cycle (TCA cycle) (purple), pentose phosphate pathway (yellow), pyrimidine metabolism (green) and purine metabolism (blue). Asterix $\left({ }^{*}\right)$ indicates metabolites that appear multiple times on the map. The pharmacological inhibition of Imd2 by mycophenolic acid (MPA) is indicated. 
Slowing transcription attenuates cordycepin's effect on alternative polyadenylation.

We and others have previously shown that the use of distal polyadenylation sites is linked to upregulation of transcriptional initiation (Swaminathan and Beilharz, 2016) and elongation rate (Pinto et al., 2011). To test the idea that a change in nucleotide metabolism caused by cordycepin treatment leads to an increase in transcription rate and thus use of $\operatorname{distal}$ poly $(\mathrm{A})$ sites, 4-thiouracil (4tU) labelling was used. This method monitors newly synthesised transcripts through the incorporation of $4 \mathrm{tU}$, which subsequently appears as a $\mathrm{T}$ to $\mathrm{C}$ conversion when sequenced. Wild-type BY4741 cells were treated with cordycepin or DMSO and 4tU for 40 minutes. mRNA was then analysed using a modified version of the mPAT approach that used an anchored oligo-dT (TV12VN) primer for reverse transcription to focus on APA. For the gene OM14, three major cleavage sites were detected (fig. 6A).

Treating cells with cordycepin caused increased use of the most distal of these alternate cleavage sites. In 4tU labelled samples, control cells had all three isoforms newly synthesised whereas, in cordycepin treated cells, the majority of new transcripts were cleaved at the most distal cleavage site. Therefore, the increased use of longer 3' UTR isoforms was not a result of changed stability between the different isoforms but was in fact due to the distal cleavage site being preferentially used in new transcripts. However, the total incorporation of $4 \mathrm{tU}$ did not significantly change between DMSO and cordycepin samples (mean incorporation of $1.011 \%$ in DMSO samples and $0.779 \%$ in cordycepin samples, $\mathrm{p}$-value $=0.227,95 \% \mathrm{Cl}=$ 1.329 to 0.866$)$. We argue that this was due to dilution of the label by the de novo nucleotide biosynthesis induced by cordycepin. As a result, an increased transcriptional rate by cordycepin could not be confirmed by an increased rate of $4 \mathrm{tU}$ incorporation. reasoned that if the change in cleavage site use was caused by cordycepin increasing the transcription rate, a slow polymerase should be able to override this effect. When the rpb1-1 mutant was complemented with a plasmid-borne copy of wild-type RPB1 (Kaplan et al., 2012), cordycepin caused a shift towards the usage of distal cleavage sites (fig. 6B). However, rpb1-1 complemented with a slow allele of $r p b 1$ (H1085Y mutation (Kaplan et al., 2012)), did not display this change. Therefore, slowing the global elongation rate ablated cordycepin's effect on 3' end processing. This observation was consistent with the idea that cordycepin did indeed promoter alternative polyadenylation by altering the rate of transcription. 
A.

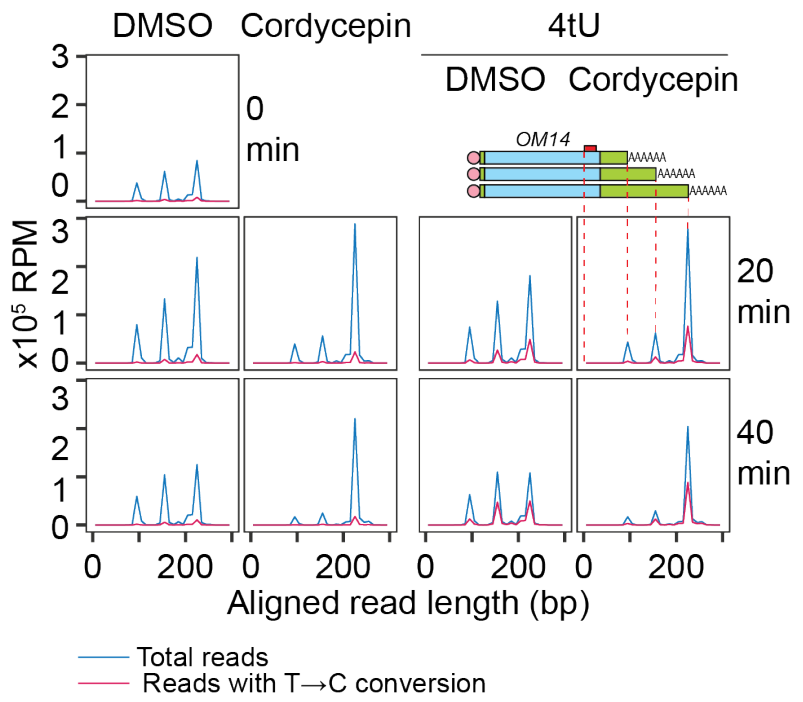

C.

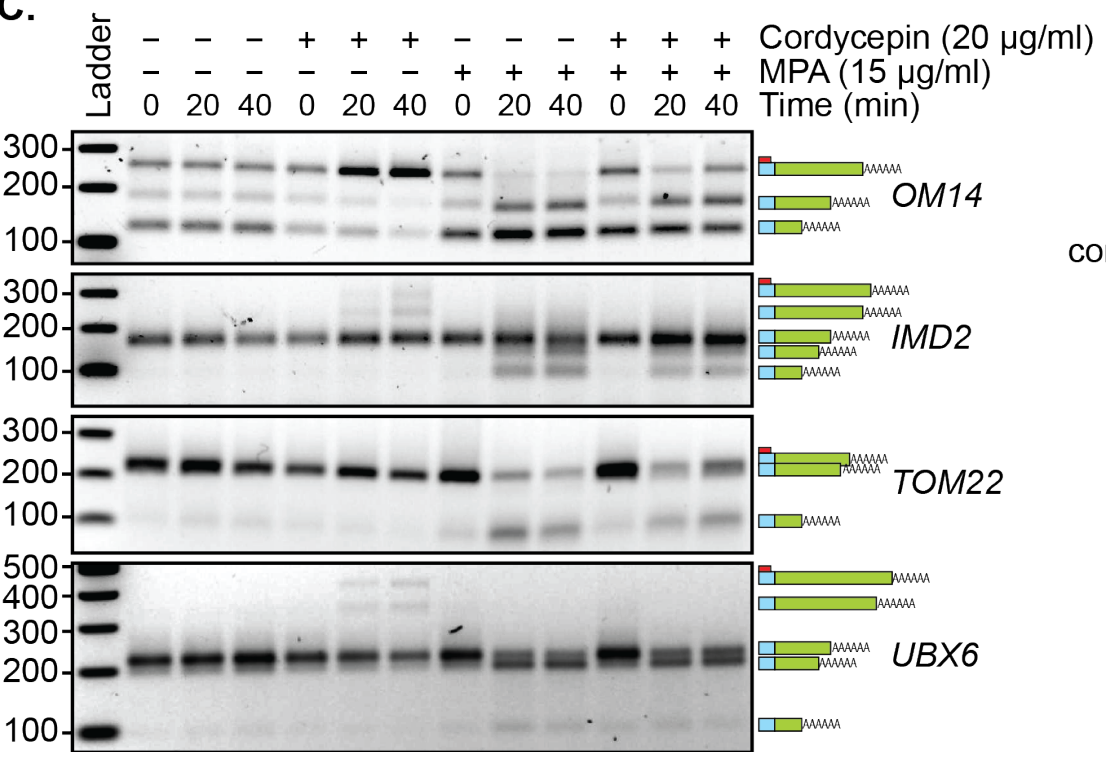

B.

Complement

Mutant

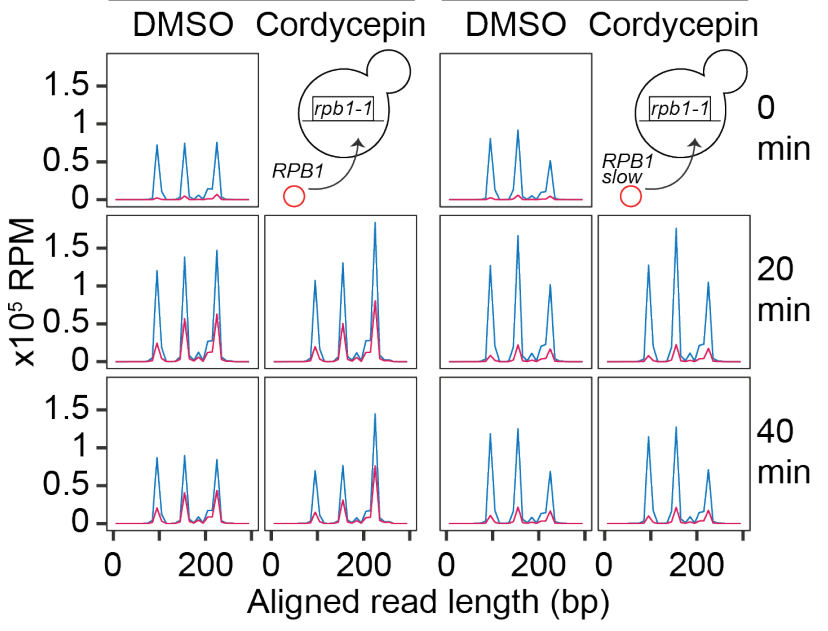

D.

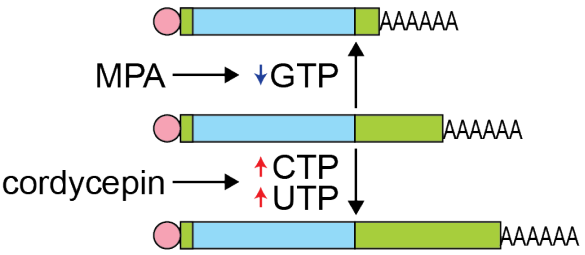

\section{Figure 6. Genetic or pharmacological slowing of transcription attenuates cordycepin's effect on} alternative polyadenylation.

A. and B. Yeast cells treated with $20 \mu \mathrm{g} / \mathrm{ml}$ cordycepin or DMSO (control) and 4tU labelled for 20 or 40 minutes. mRNA was then analysed using the mPAT approach. Reads with $\mathrm{T}$ to $\mathrm{C}$ conversions represent transcripts synthesised during the 4tU labelling and thus newly produced mRNA. The 3' ends of reads aligned to the gene $O M 14$, with the forward primer at 0 , are shown in $\times 10^{5}$ reads per million. This was done for A. Wild-type BY4741 cells and B. rpb1-1 mutant cells complemented with RPB1 or an rpb1 slow mutation. Data is representative of two biological replicates.

C. TVN-PAT analysis of the genes OM14, IMD2, TOM22 and UBX6 for yeast cells treated with $20 \mathrm{\mu g} / \mathrm{ml}$ cordycepin and $15 \mu \mathrm{g} / \mathrm{ml}$ MPA for 20 or 40 minutes. Samples were run relative to a $100 \mathrm{bp}$ ladder. Bands correspond to the different APA isoforms of the gene with slower migrating bands indicating a more distal cleavage site and faster bands a more proximal cleavage.

D. Schematic illustration of the pharmacological induction of APA. MPA treatment decreases GTP availability resulting in shorter 3'UTRs whereas cordycepin treatment increases CTP and UTP concentrations and promotes $3^{\prime} U T R$ lengthening. 
Mycophenolic acid (MPA) is an inhibitor of IMP dehydrogenase, the rate-limiting enzyme in de novo GTP synthesis. MPA treatment consequently interferes with transcription elongation due to substrate limitation (Mason and Struhl, 2005). To further demonstrate that cordycepin's APA effect was mediated by changes to nucleotide levels that in turn affected the transcriptional rate, cells were treated with $15 \mu \mathrm{g} / \mathrm{ml} \mathrm{MPA}$. Consistent with the idea that APA hinges on nucleotide levels, we found that MPA indeed caused increased usage of proximal cleavage sites (fig. $\mathbf{6 C}$ ). Moreover, co-treatment of $20 \mu \mathrm{g} / \mathrm{ml}$ cordycepin with MPA led to a suppression of this shortening (fig. $\mathbf{6 C}$ ). Collectively, these observations suggested that altered RNAP II elongation rate, as a consequence of nucleotide availability, was able to promote APA (fig. 6D).

The ability of a gene to undergo alternative polyadenylation is dependent on the local nucleosome landscape.

A large proportion of the yeast genome displayed changes in alternative polyadenylation following cordycepin treatment. But why did specific genes alter their 3' ends in response to both loss of the core cleavage machinery and the drug cordycepin whilst others did not? To address this question, we assessed the structural differences between genes that responded to cordycepin treatment and those that maintained their original cleavage sites.

For this analysis, genes were considered to be alternatively polyadenylated if more than $40 \%$ of reads switched to another cleavage site following cordycepin treatment and to not undergo alternative polyadenylation if the same cleavage site was primarily used in treated and untreated cells. This was a more stringent classification of APA than was utilised in the end-shift test in figure 3B above. On average, genes with a high level of APA were significantly longer than those without APA ( $p$-value $=0.031$ ) with median gene coding region lengths of $1420 \mathrm{bp}$ and $1275 \mathrm{bp}$, respectively (fig. 7A; supplemental file 5). This suggested that the length of a gene may influence its ability to undergo APA.

Genes were then further classified based on the directionality of their downstream neighbouring gene (fig. 7B). If the neighbouring gene was transcribed in the same direction, the gene of interest was classified as 'tandem', whereas if the adjacent gene was transcribed in the opposite direction, this gene was termed 'convergent'. Convergent genes share a 3' end intergenic region and are referred to as 'gene pairs'. Gene pairs were divided based on whether both, one or neither genes undergo APA. 


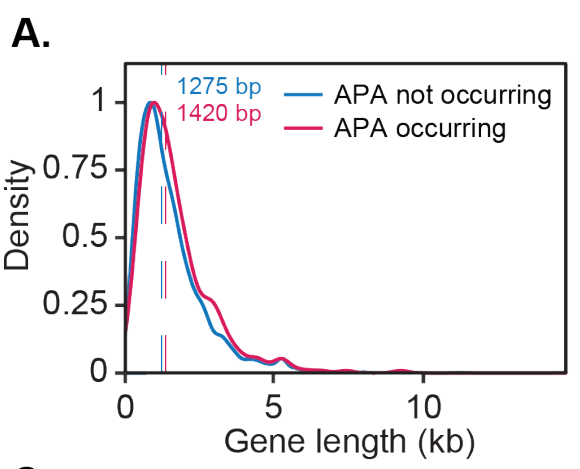

C.

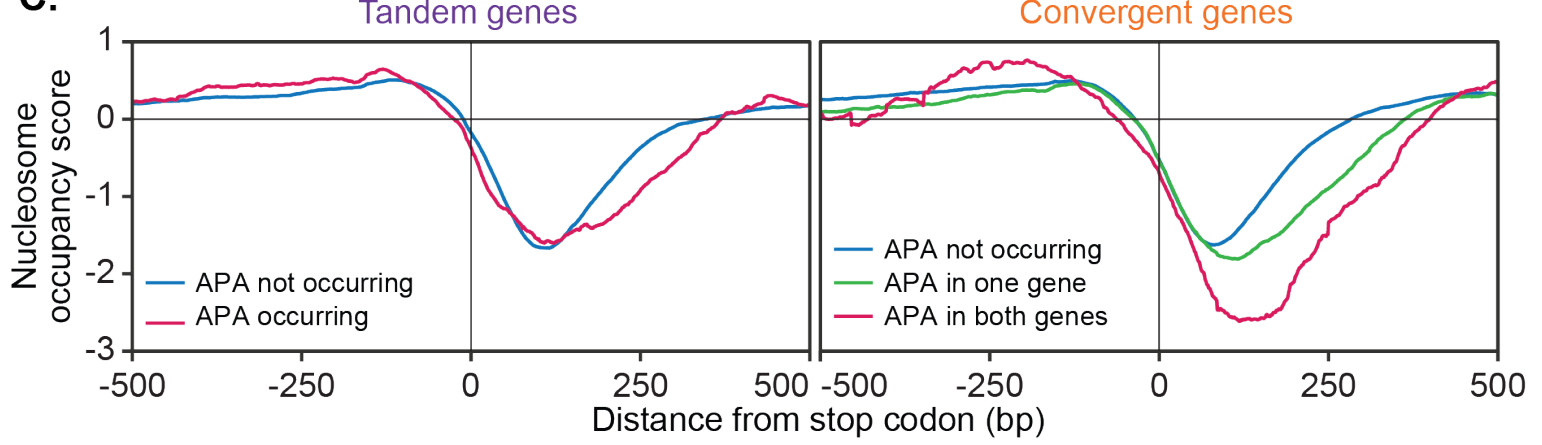

B.
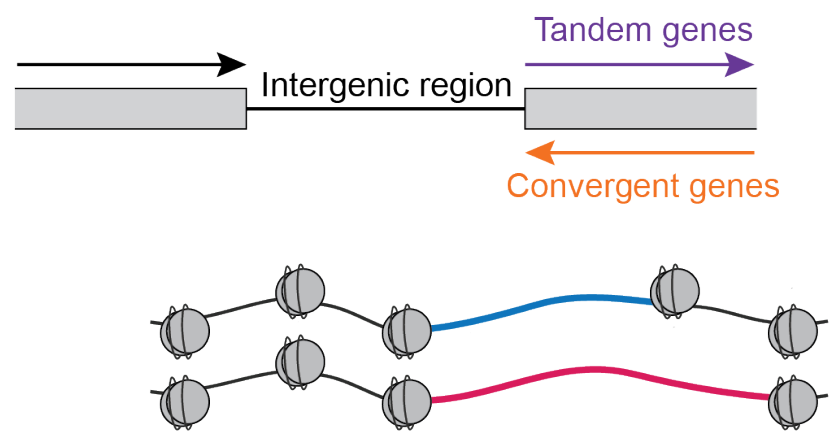

Convergent genes

Convergent genes

D.

Tandem genes

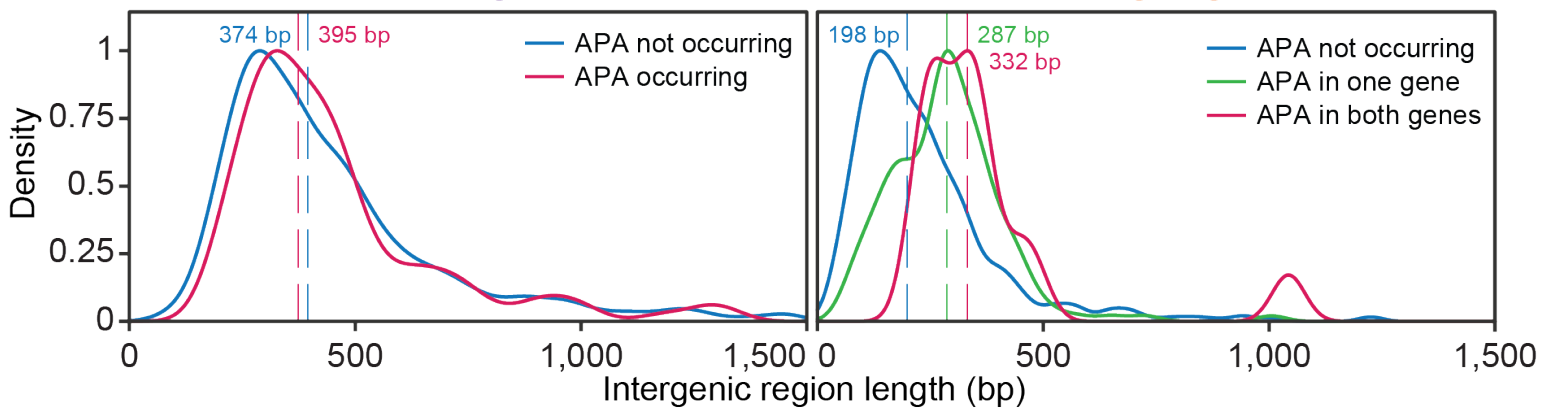

Figure 7. The ability of a gene to undergo alternative polyadenylation is dependent on the local nucleosome landscape.

Comparison of native genetic features in genes split based on APA following cordycepin treatment. APA was considered to occur if the major cleavage site (greater than $40 \%$ of reads) shifted to another site following $20 \mu \mathrm{g} / \mathrm{ml}$ cordycepin treatment for 40 minutes and to not occur if the major cleavage site remains the same.

A. Scaled density plot comparing gene length (in kilobase pairs) for genes in which APA occurs (pink, $n=$ 378) and does not occur (blue, $n=4302$ ). Dashed lines and coloured values indicate the median gene length. T-test $p$-value $=0.031$.

B. Schematic of the two types of 3' end intergenic regions. The downstream gene can either be transcribed in the same direction as the upstream gene (tandem genes) or the opposite direction (convergent genes), in which case two genes will be assigned the same $3^{\prime}$ end intergenic region.

C. Normalised nucleosome occupancy per base pair around the translation end site, averaged across all yeast genes, derived from Kaplan et al. 2009. For tandem genes, APA occurred in 128 genes (pink) and did not occur in 1719 genes (blue). T-test $p$-value $=0.055$. For convergent genes, APA occurred in both genes for 15 gene pairs (pink), in one gene for 155 pairs (green) and in neither gene for 746 pairs (blue). ANOVA $p$-value $<0.001$. Nucleosome occupancy values above zero indicate nucleosome enrichment compared to the genome-wide average. 
D. Scaled density plot comparing $3^{\prime}$ end intergenic region length (in base pairs) based on APA up to 1500 bp. Dashed lines and coloured values indicate the median intergenic region length. Tandem gene t-test $p$-value $=0.646$, convergent gene ANOVA p-value $<0.001$.

512 We next sought to determine whether the chromatin landscape of a gene correlated with alternative 513 polyadenylation. Nucleosomes are positioned at defined locations across the genome. In particular, 514 nucleosome depleted regions are associated with transcription start and stop sites (Shivaswamy et al., 515 2008, Lee et al., 2004, Xu et al., 2009, Mavrich et al., 2008). Focusing on the 3' end, we compared the native nucleosome occupancy of genes based on their responsiveness to cordycepin treatment (fig. 7C). This was done with a publicly available dataset of yeast nucleosome occupancy (Kaplan et al., 2009).

The nucleosome occupancy landscape of tandem genes did not significantly differ based on APA ( $p$-value = 0.055). However, convergent genes showed significant differences in nucleosome occupancy scores between gene pairs in which both, one and neither genes undergo APA ( $p$-value $<0.001$ ). On average, the width of the nucleosome depleted region after the stop codon was wider when alternative polyadenylation did occur. This was enhanced when both genes in a pair displayed APA. As these cells were not treated with cordycepin, it appeared that responsive convergent genes had an innately wider nucleosome depleted region at the 3' end of the gene. Therefore, a gene's alternative polyadenylation potential may be linked to a pre-determined framework of nucleosome positioning and the directionality of their neighbouring

In addition to a wider nucleosome depleted region at the $3^{\prime}$ end of the gene, cordycepin responsive convergent genes had on average a longer intergenic region between neighbouring genes (fig. 7D; median $332 \mathrm{bp}$ for APA occurring in both genes and $198 \mathrm{bp}$ for APA not occurring in either gene, $p$-value $<0.001$ ). Where one gene in a pair undergoes APA and the other did not the intergenic region length was intermediate (median $287 \mathrm{bp}$ ) compared to those in which APA occurs in both or neither gene. Increased intergenic region length may provide more room for additional cleavage sites to exist for a single gene and permit transcriptional extension without collision of transcriptional machinery between neighbouring genes. The length of the intergenic region for tandem genes did not significantly correlate with APA (median $397 \mathrm{bp}$ for APA occurring and $380 \mathrm{bp}$ for APA not occurring, $\mathrm{p}$-value $=0.856$ ). It, therefore, appears that $3^{\prime}$ end nucleosome positioning and the length of the $3^{\prime}$ end intergenic region were determinants of APA potential for convergent but not tandem genes. regulation in S. cerevisiae (fig. 8). Cleavage site choice exists as a balance between the availability of the cleavage and polyadenylation machinery, it's affinity towards the sequence elements present on the premRNA substrate and the transcriptional elongation rate. When this balance is tipped, it alters which 
cleavage site is preferentially utilised. High concentrations of the $3^{\prime}$ end processing machinery ensure processing at proximal sites and increase distal cleavage site usage.

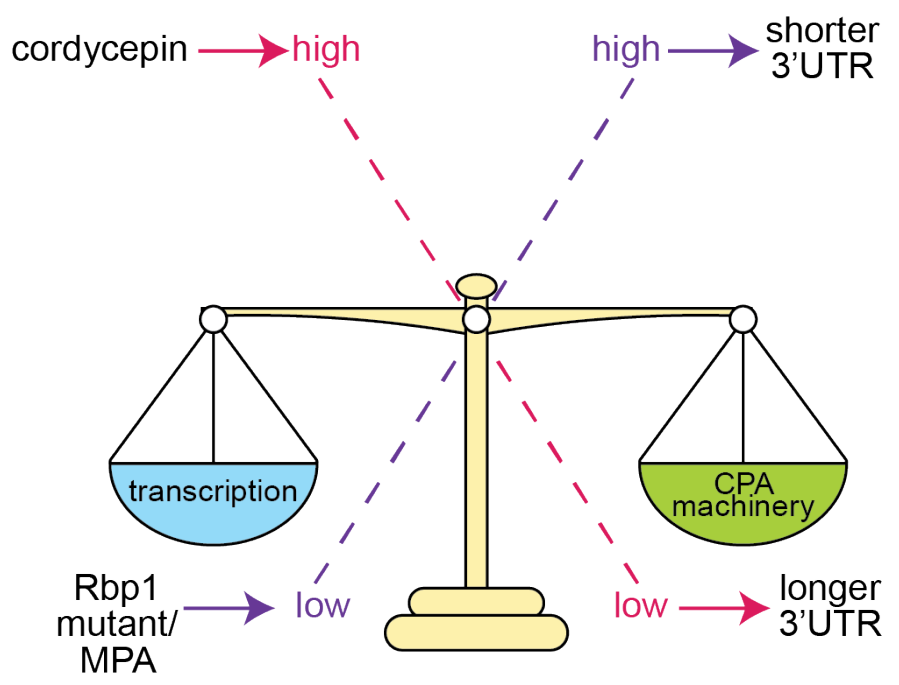

Figure 8. Proposed model of cleavage site selection in yeast.

Schematic of cleavage site selection in yeast. We propose a kinetic model where balance exists between nucleotide levels and the concentration of the cleavage and polyadenylation machinery. Tipping this scale by alteration of nucleotide concentration or mutation of cleavage factors causes changes to cleavage site choice.

555 Changing the rate of transcription has a similar impact on cleavage site choice as this shifts the ratio between transcript elongation and the availability of the $3^{\prime}$ end processing machinery. Faster transcription, as instigated by cordycepin treatment and facilitated by a permissive chromatin landscape, provides less time for the proximal site to be recognised by the cleavage factors before the distal form is also transcribed. The physical coupling of $3^{\prime}$ end formation and transcription is likely to promote the preferential usage of the longer $3^{\prime}$ UTR isoform once the distal cleavage site is available. 


\section{Discussion}

563 Despite its pervasive nature, the mechanisms of alternative polyadenylation remain poorly understood. The 564 starting point of this study was a systematic analysis of 3 ' end formation factors, which uncovered that 565 mutant alleles of most of the factors promoted global switching towards distal sites. In contrast, a subset of genes shifted toward more proximal sites when the RNA helicase Sen1 was mutated. In addition, we demonstrate that cordycepin treatment caused a global shift to distal poly(A) sites, an effect that we found to be accompanied by an accumulation of nucleotides and their biosynthetic intermediates. In agreement with the idea that changes in cellular nucleotide concentrations impacted the usage of alternative poly(A) sites following cordycepin treatment, we show that mycophenolic acid, which is known to reduce GTP levels, caused a shift to more proximal sites and combined treatment reversed the shifts observed with cordycepin alone. Furthermore, suppression of cordycepin effects by a slow rpb1 mutant of RNAP II functionally linked transcription elongation to alternative polyadenylation. Since transcription elongation is sensitive to nucleotide levels, we propose that nucleotide metabolism plays a key role in transmitting kinetic coordination of RNAP II elongation and coupled pre-mRNA $3^{\prime}$ end processing in the regulation of alternative polyadenylation.

Employing global PAT-seq and targeted mPAT approaches we found that preferred poly(A) sites in wildtype cells shifted towards more distal sites in the majority of strains carrying mutations in subunits of the canonical cleavage and polyadenylation machinery. Overall, our results indicate that gene specific roles for individual 3' end factor subunits or their expression levels play a minor part in the regulation of poly(A) site recognition for the majority of genes. Mutations in these factors can compromise efficient recognition of the more proximal sites, which are then skipped in favour of a stronger more distal site that is more readily recognised by the impaired 3' end processing machinery (Shepard et al., 2011, Beaudoing et al., 2000). However, as some genes are impacted upon mutation of individual subunits only, there also appears to be a degree of subunit specificity for alternative polyadenylation and some phenotypic variability likely can also be attributed to the specific alleles analysed in this study. Interestingly, changes in APA did not correlate with defective in vitro cleavage activity associated with mutant alleles (fig. 2B). A likely explanation for this is that reduced cleavage activity impacted the usage of alternative sites equally and thus there was no apparent shift in the cleavage site. In contrast, in vitro polyadenylation activity did correlate with defective APA in all analysed cases. The reasons for this remain unclear but the mutants analysed with defective in vitro polyadenylation also display RNA binding activity, which may be compromised giving rise to the defect in APA. The requirement for a functional CTD binding domain within Pcf11 highlighted the importance of co-transcriptional interactions for normal 3'end formation. 
reflected distinct functional roles and deficiencies, which can impact on RNA binding, subcomplex interactions and complex stability, and coupling of $3^{\prime}$ end formation to RNAP II transcription.

We observed a unique requirement for the Sen 1 helicase for poly(A) site-choice on a subset of 676 genes (fig. 3a). Sen1 function has been well characterised in association with the NNS complex where it acts to promote transcription termination of non-coding RNA and of a small number of protein coding genes (Steinmetz et al., 2006). The role played by Sen1 in alternative polyadenylation described here is distinct from the previously described roles in RNA processing because the observed sen1-1 mutant phenotype was not duplicated by nrd1-5 and nab3-11 mutations, and thus, Sen1 appeared to act independently of the RNA binding proteins Nrd1 and Nab3. In contrast, deficiency of the Nrd1-like protein Seb1 in Schizosaccharomyces pombe resulted in widespread 3' UTR lengthening demonstrating that Nrd1's role in mRNA 3' end formation has not been conserved between budding and fission yeast (Lemay et al., 2016). Here, the sen1-1 allele caused shifting towards sites proximal to those utilised in the wild-type. Therefore, functional Sen1 appeared to promote the usage of downstream poly(A) sites and thus suppressed usage of proximal poly(A) sites rather than promoting termination as was previously seen with non-coding RNA transcription. This may indicate that Sen 1 antagonised the function of the core cleavage and polyadenylation machinery, since Pcf11 was inversely required for the usage of more proximal poly(A) sites on more than $80 \%$ of the identified Sen 1 target genes. Interestingly, this activity was associated with genes that carried an above average length of the open reading frame suggesting that Sen 1 may facilitate fulllength expression of long genes. The mechanisms underlying Sen1 function in alternative polyadenylation remain unclear and need to be addressed in future studies. We speculated that defective termination of antisense non-coding RNA transcription in sen1-1 mutants facilitated transcriptional interference that in turn caused an apparent suppression of the use of distal sites on the sense mRNA transcript. Such a role would, however, be expected to involve Nrd1 and Nab3 and therefore may not apply here. Alternatively, since Sen1 does interact with the RNAP II CTD (Vasiljeva et al., 2008, Han et al., 2020), it may impact on the interaction of other CTD binding factors, like Pcf11 (Grzechnik et al., 2015), and in this way interfere with efficient $3^{\prime}$ end formation and/or termination of transcription that could shift poly(A) site usage from proximal to distal positions. Another possibility may be that Sen1 helicase activity was required to resolve RNA structures that form in proximity to the RNAP II exit channel, which may provoke transcriptional pausing and promote preferential usage of proximal sites if unresolved. Interestingly, an NNS independent requirement for Sen 1 has been reported previously in the protection of replication fork integrity that may be associated with pathology of Senataxin deficiencies (Alzu et al., 2012) but it remains unclear if this is related to Sen1 function in APA as described here. complex assembly across poly(A) sites is conserved between yeast and mammals (Baejen et al., 2014). In 
the mammalian system cleavage factor II subunits have been associated with the selection of proximal sites

633 (Kamieniarz-Gdula and Proudfoot, 2019, Ogorodnikov et al., 2018, Turner et al., 2020, Wang et al., 2019),

634 while cleavage factor I (CFIm) promotes the usage of distal sites suggesting that CFIm acts to represses 635 cleavage at proximal sites (Martin et al., 2012, Masamha et al., 2014). As no CFIm homologues are known in 636 yeast the repressive role of the core cleavage and polyadenylation machinery may not be conserved.

637 Instead, the compact nature of the yeast genome with short intergenic regions may have favoured mechanisms that promote the preferential usage of proximal poly $(A)$ site in order to avoid transcriptional interference between neighbouring genes (Gullerova and Proudfoot, 2010). The genes that require Sen1 for selection at distal sites may form a distinct group that was characterised by long open reading frames and it will be interesting to see whether the Sen 1 homologue Senataxin plays a similar role in humans.

Cordycepin's ability to terminate RNA synthesis following its incorporation into the polynucleotide chain has been widely demonstrated (Horowitz et al., 1976, Muller et al., 1977). We have previously shown that cordycepin interferes with mRNA 3' end formation independently of RNA chain termination causing 3' UTR read-through in the genes $A C T 1, A S C 1$ and $C Y H 2$ (Holbein et al., 2009) opening the possibility that the drug may impact on alternative polyadenylation. Through PAT-seq analysis we have shown here that low-dose cordycepin treatment indeed stimulated alternative polyadenylation and distal cleavage site usage globally of similar extent to those observed with 3' end factor mutants. Cordycepin effects were most comparable to shifts in pcf11-2 and ysh1-13 yeast strains. However, as no alternative polyadenylation profile of a 3 ' end 651 factor matched that of cordycepin, the drug was unlikely to act through direct interaction with specific 652 proteins. Furthermore, although cordycepin did provoke coordinated changes in 3' end factor RNA expression, only Hrp1/Nab4 showed significant changes in protein levels following a 40 minute exposure to the drug. This indicated that changes in protein levels were unlikely to cause the cordycepin induced alternative polyadenylation, which was detected within 10 minutes of drug treatment. Our metabolomics analysis revealed accumulation of nucleotides and their biosynthetic intermediates in wild-type cells exposed to cordycepin. An increase in the pool of cellular nucleotides may reduce cordycepin toxicity by dilution. This idea is in line with our previous observation that poly $(A)$ polymerase mutants displayed cordycepin resistance due to increased levels of free ATP (Holbein et al., 2009).

Importantly, nucleotide concentration is a key determinant of RNAP II processivity and elongation rate (Mason and Struhl, 2005, Uptain et al., 1997). Consistent with this idea drugs like mycophenolic acid and 6azauracil that reduce GTP and UTP levels, respectively, act synergistically with defects in trans-acting factors required for efficient elongation causing a reduced rate of nucleotide incorporation, RNAP II pausing and dissociation of RNAP II from chromatin (Exinger and Lacroute, 1992, Shaw and Reines, 2000, Mason and Struhl, 2005). The increased dwelling time of RNAP II on the chromatin template is thought to enhance the probability of associated $3^{\prime}$ end formation to take place and it was recently suggested that the rate of 
transcriptional elongation controls alternative polyadenylation (Geisberg et al., 2020). Consistent with these observations increased nucleotide levels observed following cordycepin treatment are predicted to enhance the rate of RNAP II elongation, which will reduce the window of opportunity for 3 ' end formation factors to associate with the transcript at proximal sites, and allowing for the transcription and use of distal poly(A) sites. The link between nucleotide levels and alternative polyadenylation is underscored by our observation that mycophenolic acid, which slows RNAP II transcription through reduced GTP levels, promoted usage of proximal sites and suppressed the effect of cordycepin. Similarly, a slow rpb1 allele mirrored the effects of mycophenolic acid to suppress the effects of cordycepin on alternative polyadenylation.

In addition to nucleotide levels and trans-acting factors, the structure of the chromatin template is an important parameter for RNAP II elongation. Increased nucleosome occupancy at the $3^{\prime}$ end of the gene reduces the rate of transcription due to the stalling of RNAP II (Hodges et al., 2009). This provides the 3' end formation machinery with more time to recognise this first site prior to the distal cleavage site being transcribed, meaning this position is nearly exclusively used. A stable nucleosome between potential cleavage positions is therefore predicted to provide a more proximal site with a kinetic advantage. Likewise, when the nucleosome depleted region is wider, the proximal site is expected to have less temporal advantage. Consistent with this idea we showed that genes that switch their poly(A) site in response to cordycepin treatment differ in their chromatin landscape compared to those that retain their original poly(A) sites. Convergent genes that were subject to alternative polyadenylation following cordycepin treatment tended to have wider intergenic regions downstream of the coding sequence, which likely allowed for transcriptional extension without collision of the transcriptional machinery between neighbouring genes. In contrast, no such widening of the intergenic region was observed for genes that are transcribed in tandem consistent with transcriptional interference being no issue at those genes. Moreover, we found that cordycepin-responsive convergent genes had innately wider nucleosome depleted regions at the $3^{\prime}$ end of the gene consistent with the idea that nucleosome density restricts the occurrence of alternative polyadenylation.

Taken together, our results support a model where kinetic competition governs the selection of alternative poly $(A)$ sites. On the one hand, proximal sites are transcribed first and thus carry a temporal advantage. The strength of a given poly $(A)$ site and the availability of $3^{\prime}$ end factors will determine the kinetics of cleavage and polyadenylation at those sites. Transcription of distal sites, on the other hand, will be achieved only under conditions which delay rapid processing at proximal sites and which favour rapid elongation by RNAP II. Once distal sites are available, however, they will compete with proximal sites for interaction with the $3^{\prime}$ end formation machinery. The closer vicinity to elongating RNAP II may then favour 
bioRxiv preprint doi: https://doi.org/10.1101/2020.12.01.407171; this version posted December 2, 2020. The copyright holder for this

preprint (which was not certified by peer review) is the author/funder, who has granted bioRxiv a license to display the preprint in perpetuity. It is made available under aCC-BY-NC-ND 4.0 International license.

704 complete understanding of the mechanisms of alternative polyadenylation will thus require the analysis of

705 a large number of nuclear proteins, which directly impact on gene transcription by RNAP II, chromatin

706 structure and its coupling to pre-mRNA 3' end formation. 


\section{Acknowledgements}

708 We would like to thank the following researchers for strain and plasmid resources: David Brow, Michael

709 Culbertson, Walter Keller, Lionel Minvielle-Sebastia, Beate Schwer, Mike Stark, Maurice Swanson, Françoise

710 Wyers, Craig Kaplan and Wendy Olivas. Members of the Beilharz laboratory provided critical feedback. The

711 MHTP Medical Genomics Facility, the Monash Proteomics \& Metabolomics Facility, Micromon, and the

712 Monash Bioinformatics Platform are thanked for the provision of technical support and infrastructure.

713 Monash research technology platforms are enabled by Bioplatforms Australia (BPA) and the National

714 Collaborative Research Infrastructure Strategy (NCRIS). RET was supported by an Australian Postgraduate

715 Research award. THB was supported by a Monash Bio Discovery Fellowship and grants from the ARC

716 (DP170100569 and FT180100049).

717

718

Competing interests

719 The authors declare no competing interests. 
Methods

\section{Yeast Strains and Primers}

All yeast strains and primers utilised in this study are listed in supplemental file $\mathbf{1}$ table $\mathbf{S 1}$ and Table S2 respectively.

\section{Yeast Cell Growth Conditions}

For cleavage factor mutant experiments, yeast strains were grown in YPAD rich media (1\% yeast extract, $2 \%$ peptone, $2 \%$ glucose, $100 \mu \mathrm{g} / \mathrm{ml}$ adenine hemisulphate) at $25^{\circ} \mathrm{C}$ to an $\mathrm{OD}_{600}$ of 0.6 then transferred to $37^{\circ} \mathrm{C}$ for 1 hour before cells were harvested.

For confirmation of temperature sensitivity, yeast strains were grown overnight in YPAD rich media at $25^{\circ} \mathrm{C}$. Ten-fold serial dilutions were spotted on YPAD plates (1\% yeast extract, $2 \%$ peptone, $2 \%$ glucose, 100 $\mu \mathrm{g} / \mathrm{ml}$ adenine hemisulphate, $20 \mathrm{mg} / \mathrm{ml}$ agar) and grown for 2 days at either $25^{\circ} \mathrm{C}$ or $37^{\circ} \mathrm{C}$.

For cordycepin treatment experiments, all yeast strains were grown in synthetic media $(0.67 \%$ yeast nitrogen base (without amino acids or carbohydrates; with ammonium sulphate), $2 \%$ glucose, $20 \mu \mathrm{g} / \mathrm{ml}$ uracil, $20 \mu \mathrm{g} / \mathrm{ml}$ methionine, $20 \mu \mathrm{g} / \mathrm{ml}$ histidine and $100 \mu \mathrm{g} / \mathrm{ml}$ leucine) at $30^{\circ} \mathrm{C}$ to an $\mathrm{OD}_{600}$ of $0.6 .20 \mu \mathrm{g} / \mathrm{ml}$ cordycepin, or an equal volume of DMSO (vehicle control) was then added and incubation was continued for the desired treatment lengths before cells were harvested. Where mycophenolic acid (MPA) was used, it was added at $15 \mu \mathrm{g} / \mathrm{ml}$ to cells grown exactly as for cordycepin treatment. All samples were collected immediately by centrifugation, washed with $1 \mathrm{~mL}$ ice cold milliQ H2O containing sodium azide $(0.1 \% \mathrm{w} / \mathrm{v})$ and pellets frozen at $-80^{\circ} \mathrm{C}$ until RNA extraction.

For confirmation that a non-lethal dose of cordycepin was applied, BY4741 cells were grown overnight in YPAD rich media at $30^{\circ} \mathrm{C}$. Ten-fold serial dilutions were spotted on SC plates $(0.67 \%$ yeast nitrogen base (without amino acids or carbohydrates; with ammonium sulphate), $2 \%$ glucose, $20 \mu \mathrm{g} / \mathrm{ml}$ uracil, $20 \mu \mathrm{g} / \mathrm{ml}$ methionine, $20 \mu \mathrm{g} / \mathrm{ml}$ histidine and $100 \mu \mathrm{g} / \mathrm{ml}$ leucine, $20 \mathrm{mg} / \mathrm{ml}$ agar) and grown for 2 days at $30^{\circ} \mathrm{C}$ with $20 \mu \mathrm{g} / \mathrm{ml}$ or $120 \mu \mathrm{g} / \mathrm{ml}$ cordycepin. An equivalent volume of DMSO was used as a control. cells treated with $20 \mu \mathrm{g} / \mathrm{ml}$ cordycepin for $0,5,10,20$ or 40 minutes were prepared over three separate days (six biological replicates total). Harvested cells were washed with ice cold water containing sodium 
azide $(0.1 \% \mathrm{w} / \mathrm{v})$ and frozen with liquid nitrogen. Two replicates were used for PAT-seq, six for metabolomics and five for proteomics.

\section{Total RNA extraction}

Total RNA extraction was carried out using the hot phenol method (Schmitt et al. 1990) with slight modifications. Cell pellets were resuspended in $400 \mu \mathrm{l}$ AE buffer (50 mM sodium acetate pH 5.2, $10 \mathrm{mM}$ EDTA) on ice. $33 \mu$ l of $25 \%$ SDS and $400 \mu$ lacid phenol was added then samples were vortexed and transferred to a $65^{\circ} \mathrm{C}$ water-bath for 20 minutes with intermittent vortexing. Samples were incubated on ice for 5 minutes to precipitate the SDS then centrifuged at top speed for 5 minutes at $4^{\circ} \mathrm{C}$ in a bench-top centrifuge. The supernatant (both phases) was transferred to a fresh tube and $400 \mu$ lof chloroform was added. Samples were vortexed thoroughly and centrifuged at top speed for 5 minutes at room temperature. The aqueous phase was then transferred to a fresh tube, avoiding the inter-phase and another $400 \mu \mathrm{l}$ of chloroform was added. Following vortexing and centrifugation, the aqueous phase was transferred to a fresh tube containing 1/10th volume of $3 \mathrm{M}$ sodium acetate $\mathrm{pH} 5.2$ and an equal volume of isopropanol was added. Tubes were mixed by inversion then centrifuged at top speed for 20 minutes at $4^{\circ} \mathrm{C}$. Supernatant was removed and pellets were washed with $80 \%$ ethanol and centrifuged at top speed for a further 10 minutes. Pellets were air-dried at room temperature and resuspended in RNase-free $\mathrm{dH}_{2} \mathrm{O}$.

\section{PAT-seq}

PAT-seq libraries were prepared as described previously (Harrison et al., 2015). A 5' biotinylated PATanchor primer, compatible with Illumina index primers, was used to create a $3^{\prime}$ tag on adenylated RNA. This ensures that reverse transcription only occurs from true $3^{\prime}$ ends rather than internal A repeat regions. For this $1 \mu \mathrm{g}$ total RNA was combined with $1 \mu \mathrm{l}$ Bio-EE primer and brought to a volume of $12 \mu \mathrm{l}$ with $\mathrm{dH}_{2} \mathrm{O}$ in $200 \mu \mathrm{l} \mathrm{PCR}$ tubes. Mixtures were incubated at $80^{\circ} \mathrm{C}$ for 5 minutes then cooled to $37^{\circ} \mathrm{C}$ for 5 minutes. Once cooled, tubes were flash-centrifuged and $8 \mu$ of master mix was added containing $4 \mu \mathrm{l} 5 \mathrm{x}$ SuperScript III buffer, $1 \mu \mathrm{l} 100$ mM DTT, $1 \mu \mathrm{l} 10$ mM dNTPs, $1 \mu \mathrm{l}$ RNaseOut and $1 \mu$ Klenow polymerase per reaction. Samples were mixed thoroughly by inversion then flash-centrifuged and incubated at $37^{\circ} \mathrm{C}$ for 30 minutes. The temperature was then increased to $80^{\circ} \mathrm{C}$ for 5 minutes and $80 \mu \mathrm{l}$ digest buffer $(300 \mathrm{mM} \mathrm{NaCl}, 10 \mathrm{mM}$ Tris- $\mathrm{HCl} \mathrm{pH} \mathrm{7.5)} \mathrm{added} \mathrm{before} \mathrm{incubating} \mathrm{for} \mathrm{a} \mathrm{further} 10$ minutes. Samples were then transferred to ice for 5 minutes. 
RNA was then exposed to limited fragmentation by mixing with $100 \mu \mathrm{l}$ 1:1000 diluted (with digest buffer) solution of RNase T1 for 2 minutes on ice in phase-lock tubes. This was followed by immediate phenol/chloroform RNA extraction with $200 \mu \mathrm{l}$ 1:1 acid phenol: chloroform mix and vigorous shaking to stop the reaction. After centrifugation at top speed for 5 minutes in a benchtop centrifuge, $200 \mu$ of chloroform was added, tubes were shaken and centrifuged again. The top layer was then transferred to new tubes containing $100 \mu \mathrm{l}$ streptavidin magnetic beads (pre-washed in $55^{\circ} \mathrm{C}$ digest buffer) and incubated at $37^{\circ} \mathrm{C}$ with shaking for 15 minutes to allow binding of the DNA-RNA duplex to the beads. Extended $3^{\prime}$ fragments were collected on the streptavidin magnetic beads and resuspended in $200 \mu \mathrm{l} 1 / 10^{\text {th }}$ strength $5 x$ SuperScript III buffer at $55^{\circ} \mathrm{C}$ for 5 minutes. Fragments were collected on beads again then washed with 100 $\mu l$ 1x T4 DNA ligase buffer (+ATP) at $37^{\circ} \mathrm{C}$ for 5 minutes with shaking.

5' phosphorylation of extended 3' fragments was carried out using T4 Polynucleotide Kinase. $1 \mu \mathrm{l}$ T4 Polynucleotide kinase and $19 \mu \mathrm{l}$ T4 DNA ligase buffer (+ATP) was added and samples were incubated at $37^{\circ} \mathrm{C}$ for 30 minutes with shaking. Tubes were then transferred to a $70^{\circ} \mathrm{C}$ heat block for 10 minutes then cooled slowly to room temperature to inactivate the enzyme. $200 \mu \mathrm{l}$ of $1 / 10^{\text {th }}$ strength $5 x$ SuperScript III buffer was added and samples were transferred to $200 \mu \mathrm{l}$ PCR tubes then concentrated using the beads. 7 $\mu \mathrm{l}$ of ligation master mix was added containing $2 \mu \mathrm{d} \mathrm{dH} 2 \mathrm{O}, 2 \mu \mathrm{l}$ stoichiometrically pre-annealed PAT-seq Splint A and Splint B, $3 \mu \mathrm{l} 2$ x hybridisation buffer (40\% PEG 8000, 1x SuperScript buffer) per reaction. Samples were then incubated at $65^{\circ} \mathrm{C}$ for 10 minutes then $16^{\circ} \mathrm{C}$ for 5 minutes. $8 \mu \mathrm{l} 24 \%$ PEG 8000, $2 \mu \mathrm{l} 10 \mathrm{x}$ RNL2 buffer and $2 \mu \mathrm{INN}$ ligase 2 was added and samples incubated at $16^{\circ} \mathrm{C}$ for 16 hours.

Excess $5^{\prime}$ splint was removed by adding $100 \mu \mathrm{l} 1 / 10^{\text {th }}$ strength $5 \times$ SuperScript buffer and concentrating on the magnetic beads. Reverse transcription was performed using the PAT-seq end-extend primer and SuperScript III on the magnetic matrix. $18 \mu \mathrm{l}$ master mix was added to each sample containing $11 \mu \mathrm{ld} \mathrm{H}_{2} \mathrm{O}, 4$ $\mu \mathrm{l}$ 5x SuperScript III buffer, $1 \mu \mathrm{l} 100$ mM DTT, $1 \mu \mathrm{l} 10$ mM dNTPs and $1 \mu \mathrm{l}$ RNaseOut per reaction. Samples were then incubated at $70^{\circ} \mathrm{C}$ for 5 minutes then cooled to $55^{\circ} \mathrm{C} .1 \mu \mathrm{l}$ SuperScript III was added to each tube, mixed by pipetting and incubated at $55^{\circ} \mathrm{C}$ for a further 60 minutes and heated to $70^{\circ} \mathrm{C}$ for 5 minutes.

The cDNA was size selected by elution from the beads in $2 x$ formamide gel loading buffer and electrophoresis on a 6\% urea-PAGE alongside a 25 bp DNA ladder. Fragments selected were between 125 bp and 300 bp in length.

Following gel excision, the cDNA was eluted using the "crush and soak" method. The excised gel slices were placed inside $0.5 \mathrm{ml}$ pierced lobind tubes in $2 \mathrm{ml}$ lobind tubes. These were centrifuged at $13000 \mathrm{~g}$ for 3 minutes and $300 \mu \mathrm{ldH} \mathrm{H}_{2} \mathrm{O}$ added to the bottom tube which was incubated at $4^{\circ} \mathrm{C}$ with gentle shaking overnight. Eluted material and gel slurry were transferred to a corning spin-x column and centrifuged at top speed for 3 minutes. Supernatant was then transferred to a $1.5 \mathrm{ml}$ lobind tube containing $2 \mu$ glycoblue 
and $35 \mu \mathrm{l} 5 \mathrm{M}$ ammonium acetate and mixed thoroughly. $350 \mu \mathrm{l}$ isopropanol was added and tubes were incubated on ice for 5 minutes before being centrifuged at $13000 \mathrm{~g}$ for 20 minutes at $4^{\circ} \mathrm{C}$. Pellets were then washed with $80 \%$ ethanol and air-dried before being suspended in $30 \mu \mathrm{ldH_{2 }}$ O. $10 \mu$ of the purified cDNA was used as input for amplification with $1 \mu$ PAT-seq Universal forward primer, $2 \mu$ I TruSeq Index PCR reverse primer, $50 \mu \mathrm{l} 2 \mathrm{x}$ Amplitaq Gold 360 Master Mix and $37 \mu \mathrm{ld} \mathrm{H}_{2} \mathrm{O}$. Amplification was performed with cycle conditions of $94^{\circ} \mathrm{C}$ for 10 minutes, then 16 cycles of $94^{\circ} \mathrm{C}$ for 20 seconds, $60^{\circ} \mathrm{C}$ for 20 seconds and $72^{\circ} \mathrm{C}$ for 30 seconds, followed by 1 minute at $72^{\circ} \mathrm{C}$. A different TruSeq primer was used for each experimental condition. PAT-seq libraries were sequenced on the Illumina Hiseq 1500 platform with 100 base rapid chemistry per the manufacturer's instructions at the Monash Health Translation Precinct medical genomic facility in Clayton, Victoria.

mPAT libraries were prepared as previously described (Beilharz et al. 2017). To create complementary DNA (cDNA), $1 \mu \mathrm{g}$ of total RNA and $1 \mu \mathrm{l}$ of the anchor primer mPAT reverse were combined and brought to a volume of $11 \mu \mathrm{l}$ with $\mathrm{dH}_{2} \mathrm{O}$ in $200 \mu \mathrm{l} \mathrm{PCR}$ tubes. Mixtures were incubated at $80^{\circ} \mathrm{C}$ for 5 minutes then cooled to $37^{\circ} \mathrm{C}$ for 1 minute. Once cooled, tubes were flash-centrifuged and $8 \mu l$ of master mix was added containing $4 \mu \mathrm{l}$ 5x SuperScript III buffer, $1 \mu \mathrm{l} 100$ mM DTT, $1 \mu \mathrm{l} 10 \mathrm{mM}$ dNTPs, $1 \mu \mathrm{l}$ RNaseOut and $1 \mu \mathrm{l}$ Klenow polymerase per reaction. Samples were mixed thoroughly by inversion then flash-centrifuged and incubated at $37^{\circ} \mathrm{C}$ for 30 minutes. The polymerase was then inactivated by increasing the temperature to $80^{\circ} \mathrm{C}$ for 10 minutes before cooling to $55^{\circ} \mathrm{C}$ for 1 minute. At this temperature, $1 \mu$ l of SuperScript III was added to each tube and a further 10 minutes of incubation at $55^{\circ} \mathrm{C}$ was carried out prior to mixing by inversion and flash-centrifuging. This is done to maintain the temperature during the initial stages of reverse transcription and prevent internal priming. Samples were then incubated at $55^{\circ} \mathrm{C}$ for 30 minutes followed by inactivation of reverse transcription at $80^{\circ} \mathrm{C}$ for 5 minutes and cooled to $12^{\circ} \mathrm{C}$.

For PCR amplification, cDNA was diluted 1:5 with the addition of $100 \mu \mathrm{l}$ of $\mathrm{dH}_{2} \mathrm{O} .25 \mu$ diluted cDNA was added to fresh $200 \mu \mathrm{l} \mathrm{PCR}$ tubes with $75 \mu \mathrm{l}$ master mix containing $1 \mu \mathrm{l}$ mPAT reverse primer, $1 \mu \mathrm{l}$ pooled

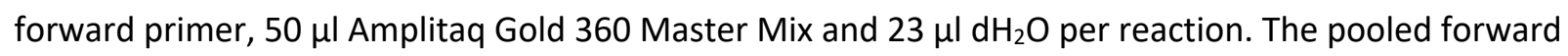
primer contained 46 gene-specific primers that each had a universal $5^{\prime}$ extension for sequential addition of the 5' (P5) Illumina elements. Amplification was performed with cycle conditions of $95^{\circ} \mathrm{C}$ for 10 minutes, then 5 cycles of $95^{\circ} \mathrm{C}$ for 30 seconds, $60^{\circ} \mathrm{C}$ for 30 seconds and $72^{\circ} \mathrm{C}$ for 30 seconds, followed by 1 minute at $72^{\circ} \mathrm{C}$. 
round of PCR amplification was carried out for each sample using $47 \mu \mathrm{l}$ purified amplicon, $1 \mu \mathrm{l} \mathrm{P5}$ universal forward primer, $2 \mu$ l Illumina TruSeq indexed primer and $50 \mu$ I Amplitaq Gold 360 Master Mix. A different TruSeq primer was used for each experimental condition and amplification as above was repeated for 10 cycles. All PCR reactions were pooled then purified using Nucleospin columns with 1:3 diluted NT1 buffer and a final elution volume of $5 \mu \mathrm{ldH_{2 }}$ O per original sample number. mPAT sequencing was done using MiSeq Reagent kit v2 with 300 cycles (300 bases of sequencing) on the Illumina MiSeq platform according to the manufacturer's specifications at Micromon Genomics, Monash University, Australia.

\section{Sequencing Data Processing and Statistical Tests}

PAT-seq and mPAT reads were processed using the Tail Tools pipeline (Harrison et al., 2015). Read counts were produced at the level of whole genes and at the level of peaks detected by the pipeline. The reference annotation used was Ensembl Saccharomyces cerevisiae version 82 for the cordycepin PAT-seq, version 89 for the mPAT, cordycepin mTVN-PAT and NNS PAT-seq and version 93 for the rpb1 mTVN-PAT and cleavage factor PAT-seq. These counts were then used to test for differential gene expression and APA. Raw sequencing and processed data has been uploaded to GEO, accession number GSE160539 (reviewer token eponueowrzofluv).

Differential gene expression was tested for between experimental groups, using the Fitnoise library (https://github.com/pfh/fitnoise) as part of the Tail Tools pipeline, after log transforming and weighting peak counts with voom (Law et al., 2014) from the limma R package after TMM library size normalization (Robinson and Oshlack, 2010). Fitnoise is an implementation of Empirical Bayes moderated t-tests on weighted linear models as described in (Smyth, 2004). Genes for which no relevant sample had at least 10 reads were removed before testing.

Shifts in APA usage was analysed as previously described (Turner et al., 2020). Peaks were first assigned to genes with up to $400 \mathrm{bp}$ down-strand of the gene (but not proceeding into another gene on the same strand) were counted as belonging to that gene. Next, peak counts were $\log _{2}$ transformed and linear models were fitted for each peak, using TMM normalization, voom, and limma, producing as coefficients estimates of the $\log _{2}$ abundance of reads at each peak in each of two experimental conditions. For each gene, a "shift score" was then estimated using these fitted coefficients, as follows. there is a fitted coefficient $\beta_{i, j}$, and the proportion of reads for each peak within a condition is

$$
p_{i, j}=\frac{2^{\beta_{i, j}}}{\sum_{k=1}^{n} 2^{\beta_{i, k}}}
$$


A shift score $s$ is then calculated, ranging from -1 to 1 where -1 indicates all reads in condition $B$ are upstrand of condition A and 1 indicates all reads in condition B are down-strand of condition A.

$$
s=\sum_{i=1}^{n} \sum_{j=1}^{n} \operatorname{sgn}(j-i) p_{A, i} p_{B, j}
$$

where sgn is the sign function. In the simplest case of two peaks, $s$ is equal to the proportion distal peak usage in B minus the proportion distal peak usage in A.

904

905

906

The fitted coefficients $\beta_{\mathrm{i}, \mathrm{j}}$ have an associated error covariance matrix, which can be propagated through these steps by the delta method to obtain an approximate standard error associated with $s$. Shift scores and associated standard errors are calculated for each gene with two or more peaks, then the topconfects R package (Harrison et al., 2019) is used to provide "confect" inner confidence bounds on the shift scores with correction for multiple testing. Confect values are only given for significantly non-zero shifts, with a False Discovery Rate of 0.05 . Ordering results by absolute confect values and reading down this list only as far as is desired, a False Coverage-statement Rate of 0.05 is guaranteed for these confidence bounds.

For mPAT experiments, we use the same $s$ statistic as above, but with a simplified calculation method. Comparing two samples, $\mathrm{A}$ and $\mathrm{B}$, with $c_{A, j}$ and $c_{B, j}$ read count at each peak $j$ respectively we calculate $p_{i, j}$ as

and calculate $s$ as above.

\section{Metabolomics}

Cell pellets obtained from $10 \mathrm{ml}$ culture at $\mathrm{OD}_{600}$ of 0.6 were resuspended in equal volume $(10 \mu \mathrm{l}) \mathrm{H} 2 \mathrm{O}$ and cells broken open with cryo-pulverisation using a Retsch CryoMill ( 50 small ball bearings per sample, 4 × 45 seconds at a frequency of $30 \mathrm{~Hz}$ with intermittent cooling in liquid nitrogen for 1 minute). $140 \mu \mathrm{l} \mathrm{CMW}$ extraction solvent (1:3:0.8 chloroform:methanol:H2O v/v/v containing the internal standards $1 \mu \mathrm{M}$ CHAPS, $1 \mu \mathrm{M}$ CAPS, $1 \mu \mathrm{M}$ PIPES and $1 \mu \mathrm{M}$ TRIS) was added and samples vortexed intermittently with ball bearings for 5 minutes ( 20 seconds vortexing, 40 seconds on ice). Supernatant and cell debris were moved to a fresh 
tube and intermittent vortexing continued for 15 minutes. Samples were then centrifuged at top speed for 10 minutes at $4^{\circ} \mathrm{C}$. Supernatant was extracted and stored at $-80^{\circ} \mathrm{C}$ until analysis by liquid chromatographymass spectrometry.

Chromatography was performed using a Dionex Ultimate 3000 UHPLC system (Thermo) and a ZIC-pHILIC column (Merck) with ammonium carbonate and acetonitrile in the mobile phase (Creek et al., 2013) coupled to a Q-Exactive high resolution mass spectrometer (Thermo). The instrument was operated in both positive and negative ion mode. Parameters for the high-performance liquid chromatography and mass spectrometry analysis were as previously described (Stoessel et al., 2016).

Untargeted metabolomics data analysis was performed using the freely availably software packages mzMatch (Scheltema et al., 2011) and IDEOM (Creek et al., 2012) as previously described (Trochine et al., 2014, Stoessel et al., 2016). 226 authentic metabolites were used for verification of retention times and to aid metabolite identification. Identification of metabolites with these standards have high confidence (MSI level 1) and are highlighted yellow in supplemental file 4. Other metabolites were putatively identified (MSI level 2-3) using exact mass and predicted retention times from KEGG, Lipidmaps and MetaCyc databases (Creek et al., 2011). Mean peak height was used for relative quantification and unpaired Welch's T test used for statistical analysis. Data was not normalised, with analysis of the four spiked internal standards (CHAPS, CAPS, PIPES and TRIS), total ion current chromatograms, median peak heights and pooled quality control samples analysed throughout the batch used to determine signal reproducibility. It is noted that one replicate from each time point was excluded during analysis due to the observation of

Gene and intergenic region length and nucleosome occupancy analysis

Alternative polyadenylation was based on the cordycepin PAT-seq experiment. Reads per million for each peak and sample were calculated using edgeR's TMM library size correction. A primary peak was assigned for each gene for untreated BY4741 cells (t0) and cells treated with $20 \mu \mathrm{g} / \mathrm{ml}$ cordycepin for 40 minutes (t40). The primary peak must have at least RPM $\geq 5$ and account for at least $40 \%$ of reads for that gene at that time point. Where no primary peak was assigned, the gene was discarded. 4410 genes had a primary peak at both $\mathrm{t} 0$ and $\mathrm{t} 40$. If the primary peak differed at $\mathrm{t} 0$ and $\mathrm{t} 40$, the gene was considered to undergo APA whereas if the primary peak remained the same after cordycepin treatment, no APA has occurred. The reference annotation used was Ensembl Saccharomyces cerevisiae version 82. Gene and intergenic region width were plotted as scaled density plots so that density peaks for APA and non-APA genes were 
genes undergoing APA and 4032 genes not undergoing APA. To test whether there was a significant difference between gene length in APA vs. non-APA genes an unpaired two-sided t-test was used. This returned a value of $p=0.031$ indicating that the difference was significant.

Using the GenomicRanges package (Lawrence et al., 2013), intergenic regions annotations were created by finding the difference between unannotated chromosomes and the ENSEMBL gene annotations. This was not strand-specific so that intergenic regions are based on genes being on either strand. These were then assigned to the upstream gene so that each allocated intergenic region is at the $3^{\prime}$ end of its gene.

Intergenic regions were further characterised into tandem and convergent based on the directionality of their $3^{\prime}$ end neighbour gene. The gene on the other side of the intergenic region was classified as either going in the same direction as the primary gene ('tandem') or in the opposite direction ('convergent'). Tandem gene intergenic regions are only assigned to one primary gene as they are on the 3' end of one gene and the $5^{\prime}$ end of the neighbouring gene whereas convergent gene intergenic regions are on the 3' end of two genes and are therefore assigned to two genes, or a 'gene pair'. 1847 genes were characterised as tandem and 2405 genes as convergent.

For tandem genes, 128 genes undergo APA and 1719 genes do not. When limited to an intergenic region width of $1500 \mathrm{bp}$ (due to outliers of up to $4670 \mathrm{bp}$ ), 125 genes undergo APA and 1677 do not. To test whether there was a significant difference between tandem gene intergenic region length in APA vs. nonAPA genes an unpaired two-sided t-test was used. This returned a value of $p=0.856$ when considering all genes and $p=0.646$ when including only intergenic regions up to $1500 \mathrm{bp}$ indicating that the difference was

Convergent gene pairs were split based on whether both genes undergo APA, one gene undergoes APA or neither gene undergoes APA. Pairs for which APA information was not available for both genes were discarded. APA occurred in both genes for 15 gene pairs (30 genes), in one gene for 155 gene pairs (310 genes) and in neither gene for 746 gene pairs (1492 genes). To test whether there was a significant difference between convergent gene intergenic region length based on APA, analysis of variance (ANOVA) was used. This returned a value of $p<0.001$ indicating that the difference was significant. from log-phase cells grown in YPD treated with micrococcal nuclease (MNase). $\log _{2}$ normalised nucleosome occupancy per base pair values were used. Genes were characterised as above as tandem or convergent and then split based on APA. Nucleosome positioning data for $500 \mathrm{bp}$ either side of the translational end site for each gene was then averaged for each category. A nucleosome occupancy value of 
0 represents the genome-wide average. Values above zero indicate nucleosome enrichment relative to the genome-wide average and values below zero a relatively nucleosome depleted region. To test whether there was significant difference in $3^{\prime}$ end nucleosome occupancy based on APA, an unpaired two-sided ttest was used for tandem genes and ANOVA was used for convergent genes. These returned values of $p=$ 0.055 and $p<0.001$ respectively indicating that the difference was significant convergent genes but not tandem genes.

\section{4tU Labelling}

1005

BY4741 cells were grown in synthetic media $(0.67 \%$ yeast nitrogen base without amino acids, $2 \%$ glucose, $20 \mu \mathrm{g} / \mathrm{ml}$ uracil, leucine $100 \mu \mathrm{g} / \mathrm{ml}$, histidine $20 \mu \mathrm{g} / \mathrm{ml}$, methionine $20 \mu \mathrm{g} / \mathrm{ml}$ ) at $30^{\circ} \mathrm{C}$. The Pol II mutant rpb1-1 cells (Olivas and Parker, 2000), carrying plasmids either with either RPB1 wild type (pCK859) or the rpb1 H1085Y slow mutation (pCK870) (Kaplan et al., 2012, Malik et al., 2017) were grown in synthetic media $\left(0.67 \%\right.$ yeast nitrogen base without amino acids, $2 \%$ glucose, $20 \mu \mathrm{g} / \mathrm{ml}$ uracil) at $30^{\circ} \mathrm{C}$.

4tU labelling was carried out according to the timelapse-seq method (Schofield et al., 2018) with modifications for the yeast model system. This involves the use of 4-thiouracil (4tU) rather than 4thiouradine (4sU), which, is readily taken up by yeast cells (Munchel et al., 2011) without expressing a nucleoside transporter (Miller et al., 2011). Once cell cultures reached an $\mathrm{OD}_{600}$ of 0.6 , an untreated sample was harvested, and the remaining cells were split into 4 flasks. $20 \mu \mathrm{g} / \mathrm{ml}$ cordycepin or an equivalent volume of DMSO (vehicle control) was added to each flask along with $500 \mu \mathrm{M} 4 \mathrm{tU}$ or an equivalent volume of DMSO (unlabelled vehicle control). Samples were taken after 20 and 40 minutes. Due to the lightsensitive nature of $4 \mathrm{tU}$, samples were treated and total RNA extracted in a light-proof setting. $1.3 \mu \mathrm{l} 192 \mathrm{mM} \mathrm{NalO}_{4}$ and made up to $25 \mu \mathrm{l}$ with RNAse-free $\mathrm{dH}_{2} \mathrm{O}$. Samples were incubated at $45^{\circ} \mathrm{C}$ for 1 hour prior to cooling on ice. $\mathrm{NaIO}_{4}$ was precipitated with $300 \mathrm{mM}$ sodium acetate $\mathrm{pH} 5.2$ and $300 \mathrm{mM}$ potassium chloride for 10 minutes on ice then centrifuged at top speed for 30 minutes at $4^{\circ} \mathrm{C}$ in a benchtop centrifuge. The supernatant was transferred to a fresh tube and RNA was precipitated with 2.5 volumes of $100 \%$ ethanol and $0.5 \mu l 5 \mathrm{mg} / \mathrm{mL}$ glycogen for 1 hour on ice. These were centrifuged at top speed for 30 minutes at $4^{\circ} \mathrm{C}$. Supernatant was removed and pellets were washed with $80 \%$ ethanol and centrifuged at top speed for a further 10 minutes. Pellets were air-dried at room temperature and resuspended in $18 \mu l$ RNase-free $\mathrm{dH}_{2} \mathrm{O}$. 
1033

1034

1035

1036

1037

1038

1039

1040

1041

1042

1043

1044

1045

1046

1047

1048

1049

1050

1051

1052

1053

1054

1055

1056

1057

1058

Zymo RNA Clean \& Concentrator-5 kit per manufacturer's instructions for total RNA and eluted in $15 \mu$ l of $\mathrm{dH}_{2} \mathrm{O}$.

An altered version of the mPAT assay involving a mTVN-PAT reverse primer rather than the MPAT reverse was used. This primer has an identical primer sequence to the mPAT reverse except for the addition of two $3^{\prime}$ variable bases, $\mathrm{V}(\mathrm{A}, \mathrm{G}$ or $\mathrm{C}$ ) and $\mathrm{N}$ (any base). These variable bases lock the primer to the polyadenylation site for reverse transcription.

To create mTVN-PAT cDNA, 400ng of total RNA and $1 \mu \mathrm{l}$ of the mTVN-PAT reverse were combined and brought to a volume of $12 \mu \mathrm{l}$ with $\mathrm{dH}_{2} \mathrm{O}$ in $200 \mu \mathrm{l}$ PCR tubes. Mixtures were incubated at $80^{\circ} \mathrm{C}$ for 5 minutes then cooled to $42^{\circ} \mathrm{C}$ for 1 minute. Once cooled, tubes were flash-centrifuged and $7 \mu l$ of master mix was added containing $4 \mu \mathrm{l}$ 5x SuperScript III buffer, $1 \mu \mathrm{l} 100$ mM DTT, $1 \mu \mathrm{l} 10$ mM dNTPs and $1 \mu$ R RaseOut per reaction. Samples were mixed thoroughly by inversion then flash-centrifuged and held at $42^{\circ} \mathrm{C}$ for 1 minute. At this temperature, $1 \mu \mathrm{l}$ of SuperScript III was added followed by mixing by inversion and flashcentrifuging. Samples were then further incubated at $42^{\circ} \mathrm{C}$ for 15 minutes, $48^{\circ} \mathrm{C}$ for 15 minutes and $55^{\circ} \mathrm{C}$ for 15 minutes followed by inactivation of reverse transcription at $80^{\circ} \mathrm{C}$ for 5 minutes and cooling to $12^{\circ} \mathrm{C}$.

PCR amplification, sequencing and data processing were carried out as for the mPAT with 21 and 12 genespecific forward primers for the BY4741 and rpb1-1 experiments respectively and primer sequences indicated in supplemental file 1 table $\mathbf{S 2}$.

For each read aligned to the target genes, every mismatch along this sequence compared to the reference was found and a list of SNPs created. From this, the total number of $\mathrm{T}$ to $\mathrm{C}$ nucleotide conversions, indicative of $4 \mathrm{tU}$ labelling, was calculated. The total reads (in reads per million) and those with $\mathrm{T}$ to $\mathrm{C}$ conversions for each read length was compared for each sample condition. Reads aligned to the OM14 gene were plotted with values representative of two replicates. 


\section{References}

1061

1062

1063

1064

1065

1066

1067

1068

1069

1070

1071

1072

1073

1074

1075

1076

1077

1078

1079

1080

1081

1082

1083

1084

1085

1086

1087

ALZU, A., BERMEJO, R., BEGNIS, M., LUCCA, C., PICCINI, D., CAROTENUTO, W., SAPONARO, M., BRAMBATI, A., COCITO, A., FOIANI, M. \& LIBERI, G. 2012. Senataxin associates with replication forks to protect fork integrity across RNA-polymerase-II-transcribed genes. Cell, 151, 835-846.

BAEJEN, C., TORKLER, P., GRESSEL, S., ESSIG, K., SODING, J. \& CRAMER, P. 2014. Transcriptome maps of mRNP biogenesis factors define pre-mRNA recognition. Mol Cell, 55, 745-57.

BARABINO, S. M., OHNACKER, M. \& KELLER, W. 2000. Distinct roles of two Yth1p domains in 3'-end cleavage and polyadenylation of yeast pre-mRNAs. EMBO J, 19, 3778-87.

BARILLA, D., LEE, B. A. \& PROUDFOOT, N. 2001. Cleavage/polyadenylation factor IA associates with the carboxyl-terminal domain of RNA polymerase II in Saccharomyces cerevisiae. Proceedings of the National Academy of Sciences, 98, 445-450.

BEAUDOING, E., FREIER, S., WYATT, J. R., CLAVERIE, J. M. \& GAUTHERET, D. 2000. Patterns of variant polyadenylation signal usage in human genes. Genome Res, 10, 1001-10.

BEILHARZ, T. H., HARRISON, P. F., MILES, D. M., SEE, M. M., LE, U. M., KALANON, M., CURTIS, M. J., HASAN, Q., SAKSOUK, J., MARGARITIS, T., HOLSTEGE, F., GELI, V. \& DICHTL, B. 2017. Coordination of Cell Cycle Progression and Mitotic Spindle Assembly Involves Histone H3 Lysine 4 Methylation by Set1/COMPASS. Genetics, 205, 185-199.

BELENKY, P. A., MOGA, T. G. \& BRENNER, C. 2008. Saccharomyces cerevisiae YOR071C encodes the high affinity nicotinamide riboside transporter Nrt1. J Biol Chem, 283, 8075-9.

BROACH, J. R. 2012. Nutritional control of growth and development in yeast. Genetics, 192, 73-105.

CAI, L., SUTTER, B. M., LI, B. \& TU, B. P. 2011. Acetyl-CoA induces cell growth and proliferation by promoting the acetylation of histones at growth genes. Mol Cell, 42, 426-37.

CHAN, S., CHOI, E. A. \& SHI, Y. 2011. Pre-mRNA 3'-end processing complex assembly and function. Wiley Interdiscip Rev RNA, 2, 321-35.

CHEN, S. \& HYMAN, L. E. 1998. A specific RNA-protein interaction at yeast polyadenylation efficiency elements. Nucleic Acids Res, 26, 4965-74. 
bioRxiv preprint doi: https://doi.org/10.1101/2020.12.01.407171; this version posted December $2,2020$. The copyright holder for this preprint (which was not certified by peer review) is the author/funder, who has granted bioRxiv a license to display the preprint in perpetuity. It is made available under aCC-BY-NC-ND 4.0 International license.

COLGAN, D. F. \& MANLEY, J. L. 1997. Mechanism and regulation of mRNA polyadenylation. Genes Dev, 11, 2755-66.

CREEK, D. J., JANKEVICS, A., BREITLING, R., WATSON, D. G., BARRETT, M. P. \& BURGESS, K. E. 2011. Toward global metabolomics analysis with hydrophilic interaction liquid chromatography-mass spectrometry: improved metabolite identification by retention time prediction. Anal Chem, 83 , 8703-10.

CREEK, D. J., JANKEVICS, A., BURGESS, K. E., BREITLING, R. \& BARRETT, M. P. 2012. IDEOM: an Excel interface for analysis of LC-MS-based metabolomics data. Bioinformatics, 28, 1048-9.

CREEK, D. J., NIJAGAL, B., KIM, D. H., ROJAS, F., MATTHEWS, K. R. \& BARRETT, M. P. 2013. Metabolomics guides rational development of a simplified cell culture medium for drug screening against Trypanosoma brucei. Antimicrob Agents Chemother, 57, 2768-79.

DEO, P., CHOW, S. H., HAN, M. L., SPEIR, M., HUANG, C., SCHITTENHELM, R. B., DHITAL, S., EMERY, J., LI, J., KILE, B. T., VINCE, J. E., LAWLOR, K. E. \& NADERER, T. 2020. Mitochondrial dysfunction caused by outer membrane vesicles from Gram-negative bacteria activates intrinsic apoptosis and inflammation. Nat Microbiol, 5, 1418-1427.

DERTI, A., GARRETT-ENGELE, P., MACISAAC, K. D., STEVENS, R. C., SRIRAM, S., CHEN, R., ROHL, C. A., JOHNSON, J. M. \& BABAK, T. 2012. A quantitative atlas of polyadenylation in five mammals. Genome Res, 22, 1173-83.

DICHTL, B., BLANK, D., SADOWSKI, M., HUBNER, W., WEISER, S. \& KELLER, W. 2002. Yhh1p/Cft1p directly links poly(A) site recognition and RNA polymerase II transcription termination. EMBO J, 21, 412535.

DICHTL, B. \& KELLER, W. 2001. Recognition of polyadenylation sites in yeast pre-mRNAs by cleavage and polyadenylation factor. EMBO J, 20, 3197-209.

DONOHOE, D. R., COLLINS, L. B., WALI, A., BIGLER, R., SUN, W. \& BULTMAN, S. J. 2012. The Warburg effect dictates the mechanism of butyrate-mediated histone acetylation and cell proliferation. Mol Cell, $48,612-26$. 
ELEUTHERIO, E., PANEK, A., DE MESQUITA, J. F., TREVISOL, E. \& MAGALHAES, R. 2015. Revisiting yeast trehalose metabolism. Curr Genet, 61, 263-74.

ENJO, F., NOSAKA, K., OGATA, M., IWASHIMA, A. \& NISHIMURA, H. 1997. Isolation and characterization of a thiamin transport gene, THI10, from Saccharomyces cerevisiae. J Biol Chem, 272, 19165-70.

EXINGER, F. \& LACROUTE, F. 1992. 6-Azauracil inhibition of GTP biosynthesis in Saccharomyces cerevisiae. Curr Genet, 22, 9-11.

GARAS, M., DICHTL, B. \& KELLER, W. 2008. The role of the putative 3' end processing endonuclease Ysh1p in mRNA and snoRNA synthesis. RNA, 14, 2671-84.

GEISBERG, J. V., MOQTADERI, Z. \& STRUHL, K. 2020. The transcriptional elongation rate regulates alternative polyadenylation in yeast. Elife, 9.

GRABER, J. H., CANTOR, C. R., MOHR, S. C. \& SMITH, T. F. 1999. In silico detection of control signals: mRNA 3'-end-processing sequences in diverse species. Proc Natl Acad Sci U S A, 96, 14055-60.

GROSS, S. \& MOORE, C. L. 2001. Rna15 interaction with the A-rich yeast polyadenylation signal is an essential step in mRNA 3'-end formation. Mol Cell Biol, 21, 8045-55.

GRZECHNIK, P., GDULA, M. R. \& PROUDFOOT, N. J. 2015. Pcf11 orchestrates transcription termination pathways in yeast. Genes Dev, 29, 849-61.

GULLEROVA, M. \& PROUDFOOT, N. J. 2010. Transcriptional interference and gene orientation in yeast: noncoding RNA connections. Cold Spring Harb Symp Quant Biol, 75, 299-311.

GUO, Z. \& SHERMAN, F. 1996. 3'-end-forming signals of yeast mRNA. Trends in Biochemical Sciences, 21, 477-481.

HAN, Z., JASNOVIDOVA, O., HAIDARA, N., TUDEK, A., KUBICEK, K., LIBRI, D., STEFL, R. \& PORRUA, O. 2020. Termination of non-coding transcription in yeast relies on both an RNA Pol II CTD interaction domain and a CTD-mimicking region in Sen1. EMBO J, 39, e101548.

HARRISON, P. F., PATTISON, A. D., POWELL, D. R. \& BEILHARZ, T. H. 2019. Topconfects: a package for confident effect sizes in differential expression analysis provides a more biologically useful ranked gene list. Genome Biol, 20, 67. 
HARRISON, P. F., POWELL, D. R., CLANCY, J. L., PREISS, T., BOAG, P. R., TRAVEN, A., SEEMANN, T. \& BEILHARZ, T. H. 2015. PAT-seq: a method to study the integration of 3'-UTR dynamics with gene expression in the eukaryotic transcriptome. RNA, 21, 1502-10.

HODGES, C., BINTU, L., LUBKOWSKA, L., KASHLEV, M. \& BUSTAMANTE, C. 2009. Nucleosomal fluctuations govern the transcription dynamics of RNA polymerase II. Science, 325, 626-8.

HOLBEIN, S., SCOLA, S., LOLL, B., DICHTL, B. S., HUBNER, W., MEINHART, A. \& DICHTL, B. 2011. The P-loop domain of yeast Clp1 mediates interactions between CF IA and CPF factors in pre-mRNA 3' end formation. PLoS One, 6, e29139.

HOLBEIN, S., WENGI, A., DECOURTY, L., FREIMOSER, F. M., JACQUIER, A. \& DICHTL, B. 2009. Cordycepin interferes with 3 ' end formation in yeast independently of its potential to terminate RNA chain elongation. RNA, 15, 837-49.

HOROWITZ, B., GOLDFINGER, B. A. \& MARMUR, J. 1976. Effect of cordycepin triphosphate on the nuclear DNA-dependent RNA polymerases and poly(A) polymerase from the yeast, Saccharomyces cerevisiae. Arch Biochem Biophys, 172, 143-8.

JAIN, N. K. \& ROY, I. 2009. Effect of trehalose on protein structure. Protein Sci, 18, 24-36.

JANICKE, A., VANCUYLENBERG, J., BOAG, P. R., TRAVEN, A. \& BEILHARZ, T. H. 2012. ePAT: a simple method to tag adenylated RNA to measure poly(A)-tail length and other 3' RACE applications. RNA, 18, 1289-95.

JI, Z., LEE, J. Y., PAN, Z., JIANG, B. \& TIAN, B. 2009. Progressive lengthening of 3' untranslated regions of mRNAs by alternative polyadenylation during mouse embryonic development. Proc Natl Acad Sci U $S A, 106,7028-33$.

KAMIENIARZ-GDULA, K. \& PROUDFOOT, N. J. 2019. Transcriptional Control by Premature Termination: A Forgotten Mechanism. Trends Genet, 35, 553-564.

KAPLAN, C. D., JIN, H., ZHANG, I. L. \& BELYANIN, A. 2012. Dissection of Pol II trigger loop function and Pol II activity-dependent control of start site selection in vivo. PLoS Genet, 8, e1002627. 
KAPLAN, N., MOORE, I. K., FONDUFE-MITTENDORF, Y., GOSSETT, A. J., TILLO, D., FIELD, Y., LEPROUST, E. M., HUGHES, T. R., LIEB, J. D., WIDOM, J. \& SEGAL, E. 2009. The DNA-encoded nucleosome organization of a eukaryotic genome. Nature, 458, 362-6.

KESSLER, M. M., HENRY, M. F., SHEN, E., ZHAO, J., GROSS, S., SILVER, P. A. \& MOORE, C. L. 1997. Hrp1, a sequence-specific RNA-binding protein that shuttles between the nucleus and the cytoplasm, is required for mRNA 3'-end formation in yeast. Genes Dev, 11, 2545-56.

KONRAD, M. 1988. Analysis and in vivo disruption of the gene coding for adenylate kinase (ADK1) in the yeast Saccharomyces cerevisiae. J Biol Chem, 263, 19468-74.

LAW, C. W., CHEN, Y., SHI, W. \& SMYTH, G. K. 2014. voom: Precision weights unlock linear model analysis tools for RNA-seq read counts. Genome Biol, 15, R29.

LAWRENCE, M., HUBER, W., PAGES, H., ABOYOUN, P., CARLSON, M., GENTLEMAN, R., MORGAN, M. T. \& CAREY, V. J. 2013. Software for computing and annotating genomic ranges. PLoS Comput Biol, 9, e1003118.

LEE, J. V., CARRER, A., SHAH, S., SNYDER, N. W., WEI, S., VENNETI, S., WORTH, A. J., YUAN, Z. F., LIM, H. W., LIU, S., JACKSON, E., AIELLO, N. M., HAAS, N. B., REBBECK, T. R., JUDKINS, A., WON, K. J., CHODOSH, L. A., GARCIA, B. A., STANGER, B. Z., FELDMAN, M. D., BLAIR, I. A. \& WELLEN, K. E. 2014. Aktdependent metabolic reprogramming regulates tumor cell histone acetylation. Cell Metab, 20, 306319.

LEMAY, J. F., MARGUERAT, S., LAROCHELLE, M., LIU, X., VAN NUES, R., HUNYADKURTI, J., HOQUE, M., TIAN, B., GRANNEMAN, S., BAHLER, J. \& BACHAND, F. 2016. The Nrd1-like protein Seb1 coordinates cotranscriptional 3' end processing and polyadenylation site selection. Genes Dev, 30, 1558-72. 


\section{1}

MALIK, I., QIU, C., SNAVELY, T. \& KAPLAN, C. D. 2017. Wide-ranging and unexpected consequences of altered Pol II catalytic activity in vivo. Nucleic Acids Res, 45, 4431-4451.

MANDEL, C. R., BAI, Y. \& TONG, L. 2008. Protein factors in pre-mRNA 3'-end processing. Cell Mol Life Sci, 65, 1099-122.

MANDEL, C. R., KANEKO, S., ZHANG, H., GEBAUER, D., VETHANTHAM, V., MANLEY, J. L. \& TONG, L. 2006. Polyadenylation factor CPSF-73 is the pre-mRNA 3'-end-processing endonuclease. Nature, 444, 953-6.

MARTIN, G., GRUBER, A. R., KELLER, W. \& ZAVOLAN, M. 2012. Genome-wide analysis of pre-mRNA 3' end processing reveals a decisive role of human cleavage factor I in the regulation of 3' UTR length. Cell Rep, 1, 753-63.

MASAMHA, C. P., XIA, Z., YANG, J., ALBRECHT, T. R., LI, M., SHYU, A. B., LI, W. \& WAGNER, E. J. 2014. CFIm25 links alternative polyadenylation to glioblastoma tumour suppression. Nature, 510, 412-6. MASON, P. B. \& STRUHL, K. 2005. Distinction and relationship between elongation rate and processivity of RNA polymerase II in vivo. Mol Cell, 17, 831-40.

MAVRICH, T. N., IOSHIKHES, I. P., VENTERS, B. J., JIANG, C., TOMSHO, L. P., QI, J., SCHUSTER, S. C., ALBERT, I. \& PUGH, B. F. 2008. A barrier nucleosome model for statistical positioning of nucleosomes throughout the yeast genome. Genome Res, 18, 1073-83.

MAYR, C. \& BARTEL, D. P. 2009. Widespread shortening of 3'UTRs by alternative cleavage and polyadenylation activates oncogenes in cancer cells. Cell, 138, 673-84.

MCCRACKEN, S., FONG, N., YANKULOV, K., BALLANTYNE, S., PAN, G., GREENBLATT, J., PATTERSON, S. D., WICKENS, M. \& BENTLEY, D. L. 1997. The C-terminal domain of RNA polymerase II couples mRNA processing to transcription. Nature, 385, 357-61.

MILLER, C., SCHWALB, B., MAIER, K., SCHULZ, D., DUMCKE, S., ZACHER, B., MAYER, A., SYDOW, J., MARCINOWSKI, L., DOLKEN, L., MARTIN, D. E., TRESCH, A. \& CRAMER, P. 2011. Dynamic transcriptome analysis measures rates of mRNA synthesis and decay in yeast. Mol Syst Biol, 7, 458. 
MINVIELLE-SEBASTIA, L., BEYER, K., KRECIC, A. M., HECTOR, R. E., SWANSON, M. S. \& KELLER, W. 1998. Control of cleavage site selection during mRNA $3^{\prime}$ end formation by a yeast hnRNP. EMBO J, 17, 7454-68.

MULLER, W. E., SEIBERT, G., BEYER, R., BRETER, H. J., MAIDHOF, A. \& ZAHN, R. K. 1977. Effect of cordycepin on nucleic acid metabolism in L5178Y cells and on nucleic acid-synthesizing enzyme systems. Cancer Res, 37, 3824-33.

MUNCHEL, S. E., SHULTZABERGER, R. K., TAKIZAWA, N. \& WEIS, K. 2011. Dynamic profiling of mRNA turnover reveals gene-specific and system-wide regulation of mRNA decay. Mol Biol Cell, 22, 278795.

OGORODNIKOV, A., LEVIN, M., TATTIKOTA, S., TOKALOV, S., HOQUE, M., SCHERZINGER, D., MARINI, F., POETSCH, A., BINDER, H., MACHER-GOPPINGER, S., PROBST, H. C., TIAN, B., SCHAEFER, M., LACKNER, K. J., WESTERMANN, F. \& DANCKWARDT, S. 2018. Transcriptome 3'end organization by PCF11 links alternative polyadenylation to formation and neuronal differentiation of neuroblastoma. Nat Commun, 9, 5331.

OLIVAS, W. \& PARKER, R. 2000. The Puf3 protein is a transcript-specific regulator of mRNA degradation in yeast. $E M B O J, 19,6602-11$.

OZSOLAK, F., KAPRANOV, P., FOISSAC, S., KIM, S. W., FISHILEVICH, E., MONAGHAN, A. P., JOHN, B. \& MILOS, P. M. 2010. Comprehensive polyadenylation site maps in yeast and human reveal pervasive alternative polyadenylation. Cell, 143, 1018-29.

PINTO, P. A., HENRIQUES, T., FREITAS, M. O., MARTINS, T., DOMINGUES, R. G., WYRZYKOWSKA, P. S., COELHO, P. A., CARMO, A. M., SUNKEL, C. E., PROUDFOOT, N. J. \& MOREIRA, A. 2011. RNA polymerase II kinetics in polo polyadenylation signal selection. EMBO J, 30, 2431-44.

ROBINSON, J. T., THORVALDSDOTTIR, H., WINCKLER, W., GUTTMAN, M., LANDER, E. S., GETZ, G. \& MESIROV, J. P. 2011. Integrative genomics viewer. Nat Biotechnol, 29, 24-6.

ROBINSON, M. D. \& OSHLACK, A. 2010. A scaling normalization method for differential expression analysis of RNA-seq data. Genome Biol, 11, R25. 
RONDON, A. G., MISCHO, H. E., KAWAUCHI, J. \& PROUDFOOT, N. J. 2009. Fail-safe transcriptional termination for protein-coding genes in S. cerevisiae. Mol Cell, 36, 88-98.

RYAN, K., CALVO, O. \& MANLEY, J. L. 2004. Evidence that polyadenylation factor CPSF-73 is the mRNA 3' processing endonuclease. $R N A, 10,565-73$.

SADOWSKI, M., DICHTL, B., HUBNER, W. \& KELLER, W. 2003. Independent functions of yeast Pcf11p in premRNA 3'end processing and in transcription termination. EMBO J, 22, 2167-77.

SANDBERG, R., NEILSON, J. R., SARMA, A., SHARP, P. A. \& BURGE, C. B. 2008. Proliferating cells express mRNAs with shortened 3' untranslated regions and fewer microRNA target sites. Science, 320, $1643-7$.

SCHELTEMA, R. A., JANKEVICS, A., JANSEN, R. C., SWERTZ, M. A. \& BREITLING, R. 2011. PeakML/mzMatch: a file format, Java library, R library, and tool-chain for mass spectrometry data analysis. Anal Chem, $83,2786-93$.

SCHOFIELD, J. A., DUFFY, E. E., KIEFER, L., SULLIVAN, M. C. \& SIMON, M. D. 2018. TimeLapse-seq: adding a temporal dimension to RNA sequencing through nucleoside recoding. Nat Methods, 15, 221-225.

SCHULZ, D., SCHWALB, B., KIESEL, A., BAEJEN, C., TORKLER, P., GAGNEUR, J., SOEDING, J. \& CRAMER, P. 2013. Transcriptome surveillance by selective termination of noncoding RNA synthesis. Cell, 155, 1075-87.

SHAW, R. J. \& REINES, D. 2000. Saccharomyces cerevisiae transcription elongation mutants are defective in PUR5 induction in response to nucleotide depletion. Mol Cell Biol, 20, 7427-37.

SHEPARD, P. J., CHOI, E. A., LU, J., FLANAGAN, L. A., HERTEL, K. J. \& SHI, Y. 2011. Complex and dynamic landscape of RNA polyadenylation revealed by PAS-Seq. RNA, 17, 761-72.

SHIVASWAMY, S., BHINGE, A., ZHAO, Y., JONES, S., HIRST, M. \& IYER, V. R. 2008. Dynamic remodeling of individual nucleosomes across a eukaryotic genome in response to transcriptional perturbation. PLoS Biol, 6, e65.

SMYTH, G. K. 2004. Linear models and empirical bayes methods for assessing differential expression in microarray experiments. Stat Appl Genet Mol Biol, 3, Article3. 
STEINMETZ, E. J., CONRAD, N. K., BROW, D. A. \& CORDEN, J. L. 2001. RNA-binding protein Nrd1 directs poly(A)-independent 3'-end formation of RNA polymerase II transcripts. Nature, 413, 327-31.

STEINMETZ, E. J., WARREN, C. L., KUEHNER, J. N., PANBEHI, B., ANSARI, A. Z. \& BROW, D. A. 2006. Genomewide distribution of yeast RNA polymerase II and its control by Sen1 helicase. Mol Cell, 24, 735-746.

STOESSEL, D., NOWELL, C. J., JONES, A. J., FERRINS, L., ELLIS, K. M., RILEY, J., RAHMANI, R., READ, K. D., MCCONVILLE, M. J., AVERY, V. M., BAELL, J. B. \& CREEK, D. J. 2016. Metabolomics and lipidomics reveal perturbation of sphingolipid metabolism by a novel anti-trypanosomal 3-(oxazolo[4,5b]pyridine-2-yl)anilide. Metabolomics, 12.

SUGAR, A. M. \& MCCAFFREY, R. P. 1998. Antifungal activity of 3'-deoxyadenosine (cordycepin). Antimicrob Agents Chemother, 42, 1424-7.

SWAMINATHAN, A. \& BEILHARZ, T. H. 2016. Epitope-tagged yeast strains reveal promoter driven changes to 3'-end formation and convergent antisense-transcription from common 3' UTRs. Nucleic Acids Res, 44, 377-86.

TIAN, B. \& GRABER, J. H. 2012. Signals for pre-mRNA cleavage and polyadenylation. Wiley Interdiscip Rev $R N A, 3,385-96$.

TROCHINE, A., CREEK, D. J., FARAL-TELLO, P., BARRETT, M. P. \& ROBELLO, C. 2014. Benznidazole biotransformation and multiple targets in Trypanosoma cruzi revealed by metabolomics. PLoS Negl Trop Dis, 8, e2844.

TURNER, R. E., HENNEKEN, L. M., LIEM-WEITS, M., HARRISON, P. F., SWAMINATHAN, A., VARY, R., NIKOLIC, I., SIMPSON, K. J., POWELL, D. R., BEILHARZ, T. H. \& DICHTL, B. 2020. Requirement for cleavage factor IIm in the control of alternative polyadenylation in breast cancer cells. RNA, 26, 969-981. UPTAIN, S. M., KANE, C. M. \& CHAMBERLIN, M. J. 1997. Basic mechanisms of transcript elongation and its regulation. Annu Rev Biochem, 66, 117-72.

VALENTINI, S. R., WEISS, V. H. \& SILVER, P. A. 1999. Arginine methylation and binding of Hrp1p to the efficiency element for mRNA 3'-end formation. RNA, 5, 272-80. 
bioRxiv preprint doi: https://doi.org/10.1101/2020.12.01.407171; this version posted December 2,2020 . The copyright holder for this

preprint (which was not certified by peer review) is the author/funder, who has granted bioRxiv a license to display the preprint in perpetuity. It is made available under aCC-BY-NC-ND 4.0 International license.

1293 VASILJEVA, L., KIM, M., MUTSCHLER, H., BURATOWSKI, S. \& MEINHART, A. 2008. The Nrd1-Nab3-Sen1 termination complex interacts with the Ser5-phosphorylated RNA polymerase II C-terminal domain. Nat Struct Mol Biol, 15, 795-804.

WANG, R., ZHENG, D., WEI, L., DING, Q. \& TIAN, B. 2019. Regulation of Intronic Polyadenylation by PCF11 Impacts mRNA Expression of Long Genes. Cell Rep, 26, 2766-2778 e6.

XU, Z., WEI, W., GAGNEUR, J., PEROCCHI, F., CLAUDER-MUNSTER, S., CAMBLONG, J., GUFFANTI, E., STUTZ, F., HUBER, W. \& STEINMETZ, L. M. 2009. Bidirectional promoters generate pervasive transcription in yeast. Nature, $457,1033-7$.

ZHANG, Z., FU, J. \& GILMOUR, D. S. 2005. CTD-dependent dismantling of the RNA polymerase II elongation complex by the pre-mRNA 3'-end processing factor, Pcf11. Genes Dev, 19, 1572-80.

ZHAO, J., HYMAN, L. \& MOORE, C. 1999. Formation of mRNA 3' ends in eukaryotes: mechanism, regulation, and interrelationships with other steps in mRNA synthesis. Microbiol Mol Biol Rev, 63, 405-45. 
Supplemental Figures

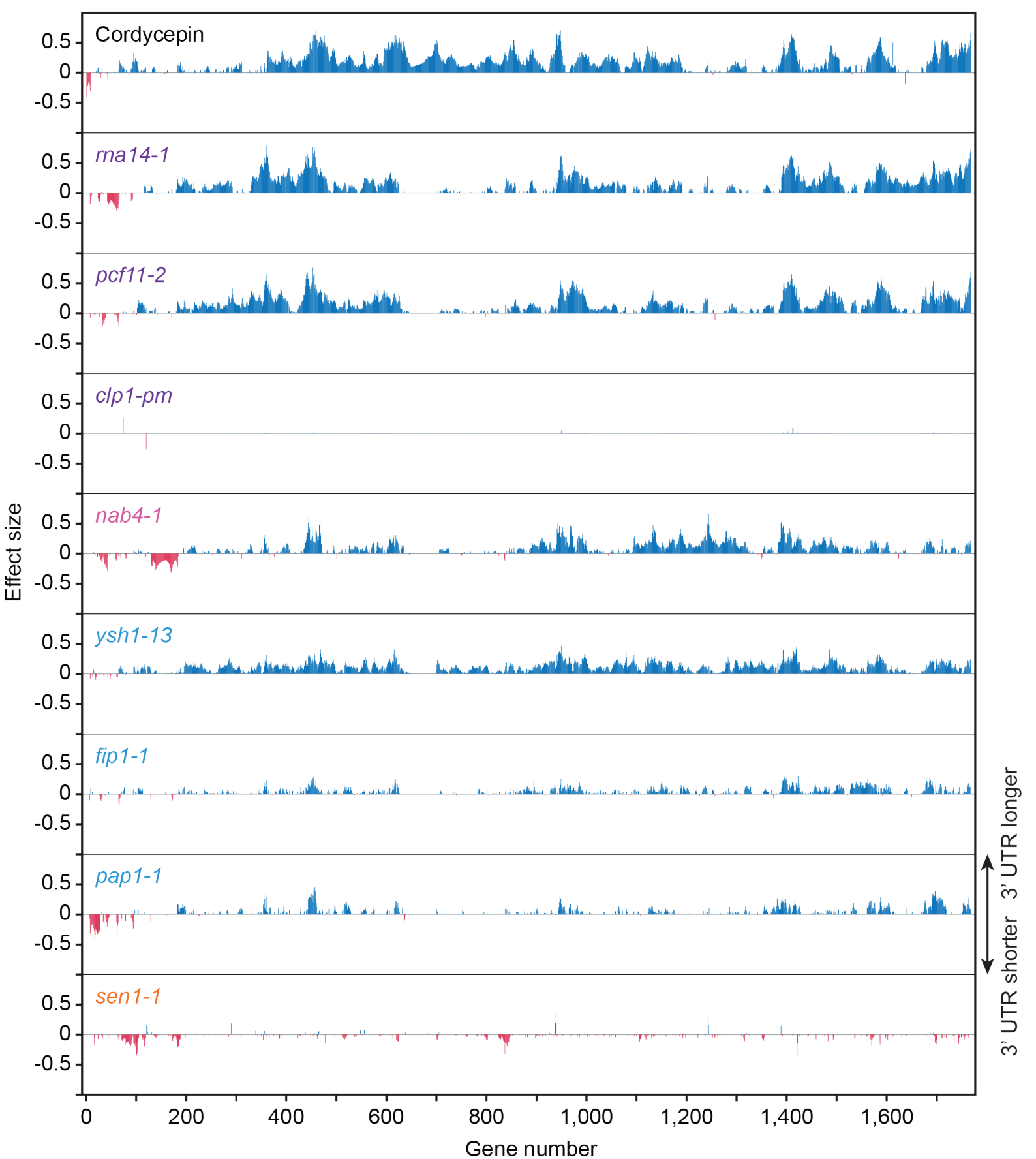

Supplemental Figure 1. Cordycepin treatment and 3' end processing factor mutant alleles promote alternative polyadenylation in subsets of genes.

Comparison of alternative polyadenylation in different genes following $20 \mu \mathrm{g} / \mathrm{ml}$ cordycepin treatment for 40 minutes or mutation of the cleavage and polyadenylation machinery. Bars correspond to $3^{\prime}$ end shift scores relative to untreated BY 4741 cells for the cordycepin samples and relative to W303 cells at $37^{\circ} \mathrm{C}$ for the mutant strains. Genes with greater than absolute 0.1 end shift confect scores for at least one condition were included (1761 genes) and numbered in arbitrary order. Blue lines indicate lengthening of the 3' UTR following cordycepin treatment or in the mutants whereas pink lines indicate shortening. Data is representative of two biological replicates. 
A.
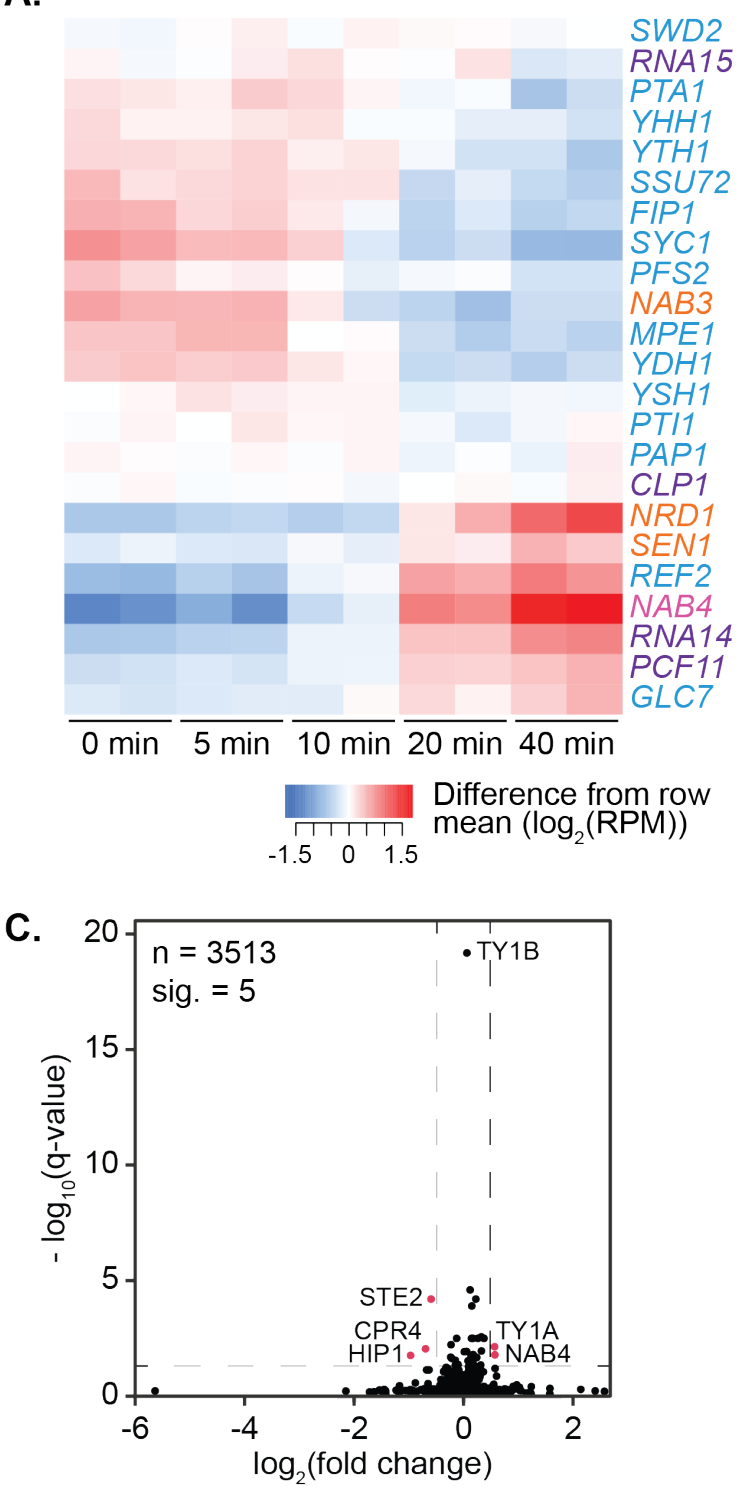

B.

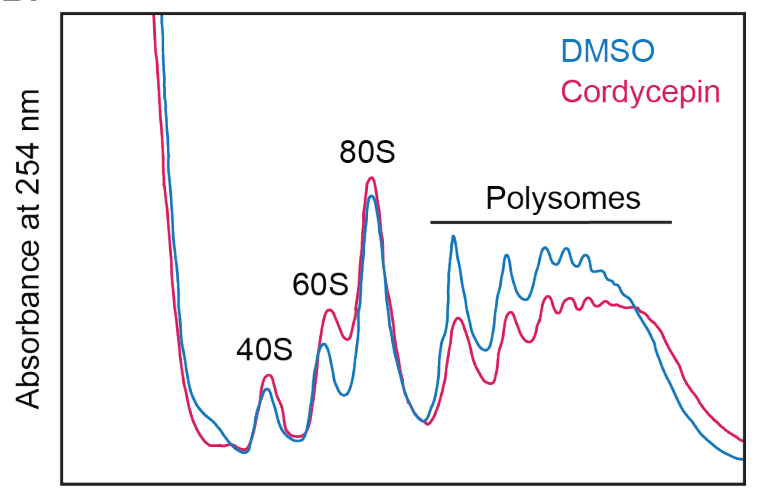

Sedimentation along sucrose gradient

D.

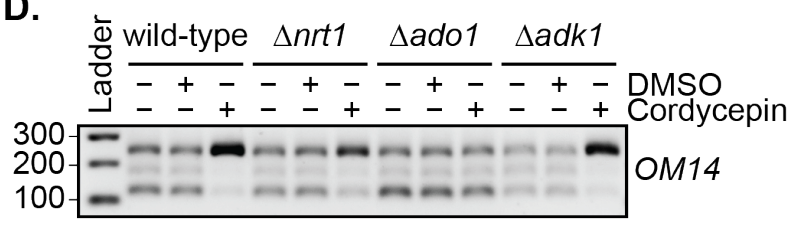

E.

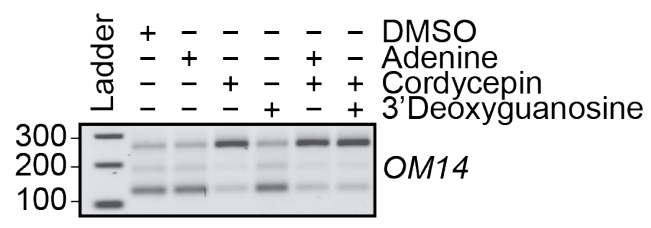

F.

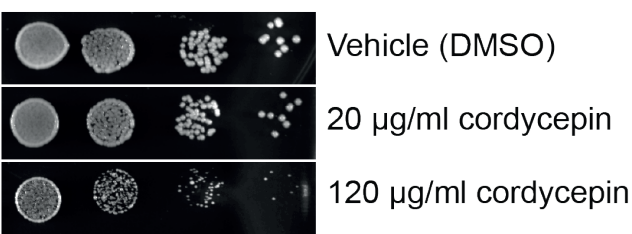

Supplemental Figure 2. Cordycepin treatment alters cleavage factor RNA expression and cellular translation.

A. Heatmap showing changes in RNA expression of the $3^{\prime}$ end processing machinery subunits following cordycepin treatment. BY4741 cells were treated with $20 \mu \mathrm{g} / \mathrm{ml}$ cordycepin for $0,5,10,20$ or 40 minutes. Red shows an increase in expression whereas blue indicates a decrease in expression at the indicated timepoints relative to the mean $\log _{2}$ reads per million expression for that gene.

B. Polysome profile of BY4741 cells treatment with DMSO (control) or $20 \mu \mathrm{g} / \mathrm{ml}$ cordycepin for 40 minutes. Cell lysate was added to a sucrose density gradient column and ultracentrifuged prior to fractionation at $254 \mathrm{~nm}$.

C. Protein fold change volcano plot for cells treated with DMSO (control) or $20 \mu \mathrm{g} / \mathrm{ml}$ cordycepin for 40 minutes. Black dots indicate all proteins identified via proteomics analysis with values above the dashed horizontal line (indicating a q-value less than 0.05 ) considered significant. Pink dots indicate genes with a q-value less than 0.05 and a fold change greater than $40 \%$.

D. TVN-PAT analysis of the gene OM14 for the indicated yeast strains treated with DMSO (control) or 20 $\mathrm{\mu g} / \mathrm{ml}$ cordycepin for 40 minutes. Samples were run relative to a $100 \mathrm{bp}$ ladder. Bands from top to bottom correspond to the distal, middle and proximal OM14 APA forms. 
E. TVN-PAT analysis of the gene OM14 for BY4741 cells treated with DMSO (control) or $20 \mu \mathrm{g} / \mathrm{ml}$ adenine, cordycepin and the guanosine equivalent $3^{\prime}$ deoxyguanosine for 40 minutes. Samples were run as for D.

F. BY4741 treated with DMSO or cordycepin as indicated were serially diluted 10 -fold onto SC media plates and grown at $30^{\circ} \mathrm{C}$ for two days.

A.
B.

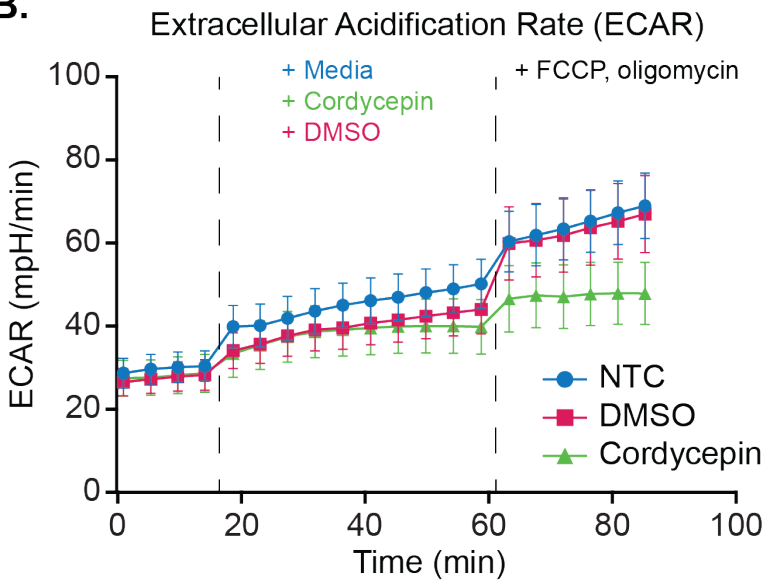

Supplemental Figure 3. Glycolytic output increase following mitochondrial stress is suppressed upon cordycepin treatment.

Seahorse metabolic flux assay mitochondrial stress analysis of cordycepin treatment. A. Oxygen Consumption Rate (OCR) and B. Extracellular Acidification Rate (ECAR) were measured to assess the rate of mitochondrial respiration and glycolysis respectively. BY4741 cell basal activity was measured for 4 cycles, prior to treatment with $20 \mu \mathrm{g} / \mathrm{ml}$ cordycepin, DMSO (control) or media (control) for 10 cycles and uncoupling of mitochondrial function via FCCP and oligomycin addition for 6 cycles. Data is representative of three independent experimental repeats consisting of 12 wells per condition in each.

\section{Supplemental File 1.}

The full list of yeast strains (Table S1) and primers (Table S2)

\section{Supplemental File 2.}

The full list of genes undergoing APA in cleavage factor, NNS subunit and cordycepin treatment PAT-seq experiments and their effect and confect values.

\section{Supplemental File 3.}

The full list of proteins found using DIA mass spectrometry on untreated cells and cells treated with cordycepin for 40 minutes. Proteins with fold changes that have significant q-values are indicated.

\section{Supplemental File 4.}

IDEOM metabolite list and metadata from HILIC metabolomics study for untreated cells and cells treated with cordycepin for 40 minutes.

\section{Supplemental File 5.}

Gene lists for cordycepin responsive and tandem/convergent genes used for gene length, intergenic region and nucleosome occupancy analyses. 


\section{Supplemental Methods}

\section{6}

\section{7}

1378

1379

1380

1381

1382

1383

1384

1385

1386

1387

1388

1389

1390

1391

1392

1393

1394

1395

1396

1397

1398

1399

1400

1401

1402

1403

1404

1405

1406

1407

1408

1409

\section{Polysome Profiling}

Prior to cell harvesting, $100 \mu \mathrm{g} / \mathrm{ml}$ cycloheximide was added and incubation continued for another minute to stall ribosomes on the mRNA. After removal of supernatant, pellets were resuspended in $5 \mathrm{ml}$ breaking

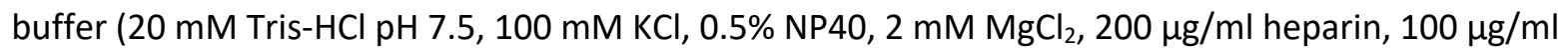
cycloheximide, $2 \mathrm{mM}$ DTT, $0.5 \mathrm{mM}$ PMSF) on ice and transferred to corex tubes. Pellets were then resuspended in $1 \mathrm{ml}$ breaking buffer and $4 \mu \mathrm{l}$ RNaseOut and approximately $500 \mu \mathrm{l}$ worth of glass beads added. Cells were lysed by vortexing corex tubes 10 times for 1 minute with 1 minute on ice in between. Supernatant was then transferred to $2 \mathrm{ml}$ tubes and stored at $-80^{\circ} \mathrm{C}$ until ready for further use. Linear sucrose gradients were prepared in Beckman Coulter 14 x $96 \mathrm{~mm}$ centrifuge tubes with sequential loading of sucrose stocks in gradient buffer $\left(50 \mathrm{mM}\right.$ Tris- $\mathrm{HCl} \mathrm{pH} \mathrm{7.0,50} \mathrm{mM} \mathrm{NH}{ }_{4} \mathrm{Cl}, 0.5 \% \mathrm{NP} 40,4 \mathrm{mM} \mathrm{MgCl}$, $1 \mathrm{mM} \mathrm{DTT}$ and $100 \mu \mathrm{g} / \mathrm{ml}$ cycloheximide). From top to bottom, tubes contained $2.5 \mathrm{ml} 17.5 \%, 2.5 \mathrm{ml} 25 \%, 2$ $\mathrm{ml} 33 \%, 2 \mathrm{ml} 41 \%$ and $2.5 \mathrm{ml} \mathrm{50 \%} \mathrm{sucrose} \mathrm{solutions.} \mathrm{Lysate} \mathrm{was} \mathrm{loaded} \mathrm{to} \mathrm{the} \mathrm{top} \mathrm{of} \mathrm{the} \mathrm{sucrose} \mathrm{gradients}$ and spun in a swinging bucket rotor Beckman Coulter SW40TI in a L-90K Preparative Ultracentrifuge at $38000 \mathrm{rpm}$ for 2.5 hours at $4^{\circ} \mathrm{C}$, max acceleration, no break. Gradients were fractionated by upward displacement with $60 \%$ sucrose at $3 \mathrm{ml} /$ minute and absorbance was monitored at $254 \mathrm{~nm}$.

\section{Proteomics}

Cell pellets were resuspended in $25 \mu \mathrm{l}$ 1\% SDC (sodium deoxycholate), $100 \mathrm{mM}$ Tris and broken open with cryo-pulverisation using a cryogenic mixer mill ( 50 small ball bearings per sample, 4 x 45 seconds at a frequency of $30 \mathrm{~Hz}$ with intermittent cooling in liquid nitrogen for 1 minute). The protein content was estimated using the bicinchoninic acid method. Samples were denatured and alkylated for 5 minutes at $95^{\circ} \mathrm{C}$ with TCEP (Tris(2-carboxyethyl phosphine hydrochloride)) and CAA (2-chloroacetamide) at final concentrations of $10 \mathrm{mM}$ TCEP and $40 \mathrm{mM}$ CAA. Sequencing-grade trypsin was added at an enzyme:protein ratio of $1: 100$ and incubated overnight at $37^{\circ} \mathrm{C}$. Protein digestion was arrested through the addition of formic acid to a final concentration of $1 \%$ and two-phase extraction with water-saturated ethyl acetate was used to remove SDC. The aqueous phase containing the peptides was collected, concentrated in a vacuum concentrator and reconstituted in buffer $\mathrm{A}$ ( $0.1 \%$ formic acid).

Data-independent acquisition (DIA) mass spectrometry was performed on an Orbitrap Fusion Tribrid mass spectrometer (Thermo Scientific) coupled to a Dionex UltiMate 3000 RSLCnano system and a Dionex UltiMate 3000 RS autosampler. The samples were loaded onto an Acclaim PepMap 100 trap column (100 
1410

1411

1412

1413

1414

1415

1416

1417

1418

1419

1420

1421

1422

1423

1424

1425

1426

1427

1428

1429

1430

1431

1432

1433

1434

1435

1436

1437

1438

1439

1440

1441

1442

1443

1444

1445

$\mu \mathrm{m} \times 2 \mathrm{~cm}$; nanoViper; C18; $5 \mu \mathrm{m} ; 100 \AA$ ) and separated on an Acclaim PepMap RSLC analytical column (75 $\mu \mathrm{m} \times 5 \mathrm{~cm}$; nanoViper; $\mathrm{C} 18 ; 2 \mu \mathrm{m} ; 100 \AA ̊)$. The parameters for the mass spectrometric DIA acquisition were described previously (Deo et al., 2020). The acquired DIA data was analysed in Spectronaut 8 Cassini (Biognosys) using an in-house generated spectral library established by acquiring the same samples with the same set-up in data-dependent acquisition mode.

\section{TVN-PAT}

TVN-PAT was performed as previously described (Janicke et al., 2012). To create TVN-PAT cDNA, 1 Mg of total RNA and $1 \mu \mathrm{l}$ TVN primer were combined and brought to a volume of $12 \mu \mathrm{l}$ with dH2O in $200 \mu \mathrm{PCR}$ tubes. Mixtures were incubated at $80^{\circ} \mathrm{C}$ for 5 minutes then cooled to $42^{\circ} \mathrm{C}$ for 1 minute. Once cooled, tubes were flash-centrifuged and $7 \mu \mathrm{l}$ of master mix was added containing $4 \mu \mathrm{l} 5 \mathrm{x}$ SuperScript III buffer, $1 \mu \mathrm{l} 100$ mM DTT, $1 \mu l 10 \mathrm{mM}$ dNTPs and $1 \mu \mathrm{l}$ RNaseOut per reaction. Samples were mixed thoroughly by inversion then flash-centrifuged and held at $42^{\circ} \mathrm{C}$ for 1 minute. At this temperature, $1 \mu \mathrm{l}$ of SuperScript III was added followed by mixing by inversion and flash-centrifuging. Samples were then further incubated at $42^{\circ} \mathrm{C}$ for 15 minutes, $48^{\circ} \mathrm{C}$ for 15 minutes and $55^{\circ} \mathrm{C}$ for 15 minutes followed by inactivation of reverse transcription at $80^{\circ} \mathrm{C}$ for 5 minutes and cooling to $12^{\circ} \mathrm{C}$.

For PCR amplification, cDNA was diluted 1:10 with the addition of $200 \mu \mathrm{l}$ of d $\mathrm{H}_{2} \mathrm{O} .5 \mu \mathrm{l}$ diluted cDNA was added to fresh $200 \mu \mathrm{l} \mathrm{PCR}$ tubes with $15 \mu \mathrm{l}$ master mix containing $0.2 \mu \mathrm{l}$ PAT assay reverse primer, $0.2 \mu \mathrm{l}$ OM14 gene-specific forward primer, $10 \mu \mathrm{l}$ Amplitaq Gold 360 Master Mix and $4.6 \mu \mathrm{d} \mathrm{d}_{2} \mathrm{O}$ per reaction. Amplification was performed with cycle conditions of $95^{\circ} \mathrm{C}$ for 10 minutes, then 28 cycles of $95^{\circ} \mathrm{C}$ for 20 seconds, $60^{\circ} \mathrm{C}$ for 20 seconds and $72^{\circ} \mathrm{C}$ for 30 seconds, followed by 1 minute at $72^{\circ} \mathrm{C}$.

$4 \mu \mathrm{l} 6 \mathrm{x}$ Orange $\mathrm{G}$ loading dye was added to each PCR sample. $12 \mu \mathrm{l}$ was run on a $2 \%$ high resolution agarose gel pre-stained with SYBR safe. To estimate PCR product sizes, band migration was determined relative to a 100 bp ladder.

\section{Seahorse}

BY4741 cells were subjected to Seahorse XF Cell Energy Phenotype assay per the manufacturer's instructions (Agilent) with modifications as follows. Cells were grown at $30^{\circ} \mathrm{C}$ to $O D_{600} 0.6$ in synthetic media then resuspended in assay medium (Seahorse XF media, $20 \mu \mathrm{g} / \mathrm{ml}$ uracil, $5 \mathrm{mg} / \mathrm{ml}$ glucose, $5 \mu \mathrm{g} / \mathrm{ml}$ ammonium sulphate) and plated ( 5 × 104 per well) in CellTak-coated XF96 plates via centrifugation (1000 g, $5 \mathrm{~min}, \mathrm{RT}$ ). After 1 hour recovery at $30^{\circ} \mathrm{C}$, Oxygen Consumption Rate (OCR) and Extracellular Acidification Rate (ECAR) were determined using an XF96 extracellular flux analyser (Seahorse Biosciences) at $30^{\circ} \mathrm{C}$. 
bioRxiv preprint doi: https://doi.org/10.1101/2020.12.01.407171; this version posted December 2, 2020. The copyright holder for this

preprint (which was not certified by peer review) is the author/funder, who has granted bioRxiv a license to display the preprint in perpetuity. It is made available under aCC-BY-NC-ND 4.0 International license.

1446 Using cycling parameters $1 \mathrm{~min} \mathrm{mix,} 1 \mathrm{~min}$ wait, 2 min measure, basal activity was measured for 4 cycles.

1447 After addition of $20 \mu \mathrm{g} / \mathrm{ml}$ cordycepin, or an equivalent volume of DMSO or assay media (controls), a

1448 further 10 cycles were measured before uncoupling of mitochondrial function via stressor cocktail ( $3 \mu \mathrm{M}$

1449 FCCP, $1 \mu \mathrm{M}$ oligomycin), followed by a further 6 measurement cycles. Data are representative of three

1450 independent experimental repeats, with 12 wells per condition in each. Graphs were prepared using Prism

14517 software.

1452 